Corrected: Author Correction

ARTICLE

https://doi.org/10.1038/s42003-019-0587-z OPEN

\title{
High-resolution crystal structure of human asparagine synthetase enables analysis of inhibitor binding and selectivity
}

\author{
Wen Zhu (10 1,10, Ashish Radadiya (1) ${ }^{1}$, Claudine Bisson 2,10, Sabine Wenzel (1) ${ }^{3}$, Brian E. Nordin ${ }^{4,11}$, \\ Francisco Martínez-Márquez ${ }^{3}$, Tsuyoshi Imasaki (1) 3,5, Svetlana E. Sedelnikova², Adriana Coricello (1) 1,6,7, \\ Patrick Baumann (10 ${ }^{1}$, Alexandria H. Berry ${ }^{8}$, Tyzoon K. Nomanbhoy ${ }^{4}$, John W. Kozarich (1) ${ }^{4}$, Yi Jin (1) ${ }^{1}$, \\ David W. Rice (1) ${ }^{2}$, Yuichiro Takagi (i) ${ }^{3}$ \& Nigel G.J. Richards (10) 1,9
}

Expression of human asparagine synthetase (ASNS) promotes metastatic progression and tumor cell invasiveness in colorectal and breast cancer, presumably by altering cellular levels of L-asparagine. Human ASNS is therefore emerging as a bona fide drug target for cancer therapy. Here we show that a slow-onset, tight binding inhibitor, which exhibits nanomolar affinity for human ASNS in vitro, exhibits excellent selectivity at $10 \mu \mathrm{M}$ concentration in HCT116 cell lysates with almost no off-target binding. The high-resolution ( $1.85 \AA$ ) crystal structure of human ASNS has enabled us to identify a cluster of negatively charged side chains in the synthetase domain that plays a key role in inhibitor binding. Comparing this structure with those of evolutionarily related AMP-forming enzymes provides insights into intermolecular interactions that give rise to the observed binding selectivity. Our findings demonstrate the feasibility of developing second generation human ASNS inhibitors as lead compounds for the discovery of drugs against metastasis.

\footnotetext{
${ }^{1}$ School of Chemistry, Cardiff University, Cardiff, UK. ${ }^{2}$ Department of Molecular Biology and Biotechnology, University of Sheffield, Sheffield, UK. ${ }^{3}$ Department of Biochemistry and Molecular Biology, Indiana University School of Medicine, Indianapolis, IN, USA. ${ }^{4}$ ActivX Biosciences, Inc, La Jolla, CA, USA. ${ }^{5}$ Division of Structural Medicine and Anatomy, Kobe University Graduate School of Medicine, Kobe, Japan. ${ }^{6}$ Dipartimento di Scienze della Salute "Magna Græcia" di Catanzaro, Viale Europa, 88100 Catanzaro, Italy. ${ }^{7}$ Net4Science academic spinoff, Università "Magna Græcia", Campus Salvatore Venuta, Viale Europa, 88100 Catanzaro, Italy. ${ }^{8}$ Department of Biology, California Institute of Technology, Pasadena, CA, USA. ${ }^{9}$ Foundation for Applied Molecular Evolution, Alachua, FL, USA. ${ }^{10}$ Present address: Department of Chemistry and California Institute for Quantitative Biosciences, University of California, Berkeley, CA, USA. ${ }^{11}$ Present address: Vividion Therapeutics, San Diego, CA, USA. Correspondence and requests for materials should be addressed to Y.

T. (email: ytakagi@iu.edu) or to N.G.J.R. (email: RichardsN14@cardiff.ac.uk)
} 
A sparagine synthetase (ASNS) catalyzes the ATPdependent biosynthesis of L-asparagine in cells from Laspartic acid using L-glutamine as a nitrogen source ${ }^{1}$. Several recent findings provide evidence for connections between asparagine biosynthesis and human disease, raising the urgency for in-depth studies of human ASNS. First, asparagine synthetase deficiency (ASD), which is a rare human neurological disorder, has been linked to residue changes at several locations throughout the enzyme ${ }^{2}$. Nothing is known about how these ASD-linked changes in ASNS impact catalytic activity and stability of the enzyme, although children with ASD exhibit microcephaly, epileptic-like seizures, and intellectual disability ${ }^{3}$. Second, silencing the gene encoding ASNS inhibits cell proliferation in a murine sarcoma model ${ }^{4}$ generated by oncogenic forms of $\mathrm{Kras}^{5,6}$. Third, L-asparagine is important for the growth and maintenance of acute lymphoblastic leukemia ${ }^{7}$, and breast $^{8}$, lung ${ }^{9}$, and castration-resistant prostate ${ }^{10}$ cancers. Finally, altering exogenous L-asparagine levels affects tumor cell invasiveness, and enforced expression of human ASNS promotes metastatic progression in both colorectal ${ }^{11}$ and breast cancer ${ }^{12}$ by an undetermined mechanism. All of these observations strongly suggest that human ASNS is a bona fide drug target and that potent, smallmolecule ASNS inhibitors will have significant clinical utility in the prevention of metastasis ${ }^{11,12}$, and perhaps more broadly in cancer chemotherapy ${ }^{13}$. In fact, it has been suggested that drugs that alter the availability of asparagine in the body might be useful to treat sarcomas with mutant forms of Ras ${ }^{4}$. Access to highly specific, small-molecule ASNS inhibitors that can penetrate cells will be transformative in establishing the feasibility of targeting ASNS as a new strategy to treat recalcitrant cancers.

Identifying compounds with nanomolar affinity for human ASNS, however, has proven to be remarkably difficult. The only reported screening studies failed to identify small-molecules with sub-micromolar binding and/or high selectivity for human ASNS $^{14}$, probably because of a lack of mechanistic and structural information about the enzyme. Early work by our group therefore elucidated the kinetic and catalytic mechanisms of the glutaminedependent asparagine synthetase (AS-B) $)^{15,16}$ encoded by the asn $B$ gene in Escherichia coli ${ }^{17}$. These studies revealed that both the $\beta$ aspartyl-AMP intermediate and the transition state for its subsequent reaction with ammonia are tightly bound by the enzyme during catalysis (Fig. 1a) ${ }^{16}$. Although unreactive analogs of the $\beta$ aspartyl-AMP intermediate are indeed sub-micromolar ASNS inhibitors $^{18}$, the functionalized methylsulfoximines $\mathbf{1}$ and $\mathbf{2}$ (Fig. 1b), which mimic the key transition state for the attack of ammonia on activated esters ${ }^{19,20}$, are slow-onset inhibitors exhibiting nanomolar affinity for the enzyme in kinetic assays ${ }^{21,22}$. Very importantly, ASNS inhibitor 1 (Fig. 1b) negatively impacts the growth of sarcoma cells in a manner similar to that seen when ASNS expression is decreased using siRNA knockdown methods ${ }^{4}$. Moreover, this compound, as a 1:1 mixture of diastereoisomers 1a and $\mathbf{1 b}$ (Fig. 1b), is cytotoxic against asparaginase-resistant MOLT-4 leukemia cells, albeit only at micromolar concentrations ${ }^{21}$. Unfortunately, although ASNS inhibitor 1 might possess anti-cancer properties, its poor bioavailability curtails its usefulness for studies employing animal models of cancer and metastasis ${ }^{21}$. Nevertheless, this cytotoxic ASNS inhibitor can serve as a starting point for drug discovery. We now report the extent to which ASNS inhibitor 1 participates in off-target binding in HCT-116 cell lysates together with the first high-resolution X-ray crystal structure of human ASNS, to our knowledge. Our studies provide an in-depth understanding of the molecular basis for the specificity of ASNS inhibitor $\mathbf{1}$ and provide a firm basis for future efforts to generate a second generation of small-molecule ASNS inhibitors with improved bioavailability and reduced chemical complexity.

\section{Results}

Binding specificity of ASNS inhibitor 1 in HCT-116 lysates. We undertook KiNativ ${ }^{\mathrm{TM}}$ chemoproteomic profiling experiments ${ }^{23}$, employing the chemically reactive probe 3 (Fig. 1) ${ }^{24}$, in HCT-116 (ATCC CCL-247) cell lysates to evaluate the affinity of ASNS inhibitor 1 for alternate targets, especially kinases and non-kinase ATPases. This cell line can metastasize in xenograft models and has been used in studies of colon cancer proliferation ${ }^{25}$. In addition, transcriptome profiling indicates that ASNS is expressed in relatively high amounts in HCT-116 cells (Supplementary Fig. 1). Additional support for the cancer relevance of this cell line is provided by recent work showing the importance of asparagine biosynthesis in colorectal cancer cell proliferation and metastasis $^{11}$. Based on the clinically relevant plasma concentration of anticancer drugs ${ }^{26}$, we incubated the probe molecule 3 with HCT-116 cell lysates in the presence $(10 \mu \mathrm{M})$ or absence of ASNS inhibitor 1. MS/MS fragmentation and sequence analysis of the tryptic peptides obtained from these reaction mixtures showed that ASNS inhibitor $\mathbf{1}$ suppressed the ability of probe $\mathbf{3}$ to acylate the side chain of Lys-466 (located within the ATP-binding site of human ASNS) to an extent of $62 \%$ when present in the HCT-116 lysate at $10 \mu \mathrm{M}$ concentration (Fig. 2). Even though this value is lower than expected, given that ASNS inhibitor $\mathbf{1}$ is a slow-onset inhibitor ${ }^{27}$ in vitro with a nanomolar $\mathrm{K}_{\mathrm{i}}^{*}\left(\right.$ ref. $\left.^{21}\right)$, acylation of the active site lysine in ASNS was inhibited to the greatest extent for all ATPases present in the cell lysates. Occupation of the ATPbinding site by ASNS inhibitor 1 will, of course, vary over time as a function of the rate at which the initial EI complex isomerizes to the $\mathrm{EI}^{*}$ complex ${ }^{28}$. The complicated environment of the cell lysate makes it difficult to quantify the in vitro isomerization rate constants, but we note that the activity of human ASNS is decreased approximately three-fold after $15 \mathrm{~min}$ in the presence of $10 \mu \mathrm{M}$ ASNS inhibitor 1 under our in vitro assay conditions ${ }^{21}$. In addition, it is also possible that the ability of ASNS inhibitor $\mathbf{1}$ to bind to the synthetase site of the enzyme is negatively impacted by the ATP concentration in the cell lysates ${ }^{21}$. Importantly, only moderate suppression of lysine acylation by the reactive probe 3 was observed for a small number of off-target enzymes, including nicotinate-nucleotide adenylyltransferase ${ }^{29}$, and argininosuccinate synthetase $(\mathrm{ASS} 1)^{30}$. There is also a weak interaction of the ASNS inhibitor 1 with the ATP-binding sites of two ABC transporters. On the other hand, $10 \mu \mathrm{M}$ ASNS inhibitor 1 does not suppress lysine acylation in the ATP-binding sites of phosphopantetheine adenylyltransferase ${ }^{31}$, GMP synthetase ${ }^{32}$, and glutamyl-tRNA synthetase ${ }^{33}$ to any significant extent even though these enzymes also convert ATP to AMP and inorganic pyrophosphate $\left(\mathrm{MgPP}_{\mathrm{i}}\right)$ during catalytic turnover (Fig. 2 and Supplementary Data 1). Although the structurally similar compound 2 (Fig. 1b) binds to the Escherichia coli ammonia-dependent asparagine synthetase (AS-A) ${ }^{34}$, which is evolutionarily related to bacterial amino-acyl tRNA synthetases ${ }^{35}$, our chemoproteomic profiling studies suggest that ASNS inhibitor 1, when present in HCT-116 cell lysates at $10 \mu \mathrm{M}$ concentration, interacts only weakly with lysyl tRNA synthetase and does not bind to seryl or asparaginyl tRNA synthetases (Fig. 2 and Supplementary Data 1). ASNS inhibitor 1 is also bound by UMP-CMP kinase 1 $(\mathrm{CMPK} 1)^{36}$ and (to a considerably lesser extent) the kinases MVK, CMPK2, and AK1. In efforts to rationalize the interaction of CMPK1 and ASNS inhibitor 1, and assuming that binding takes place in the ATP-binding site of the kinase, we used manual docking methods to obtain a model of the 1a/CMPK1 complex based on the X-ray crystal structure of the homologous enzyme in Dictyostelium discoideum ${ }^{37}$ bound to ADP (Supplementary Fig. 2). Although this model suggests that both epimers $\mathbf{1 a}$ and $\mathbf{1 b}$ could possibily interact with the kinase (see Supplementary Information), any in-depth understanding of their binding 
a

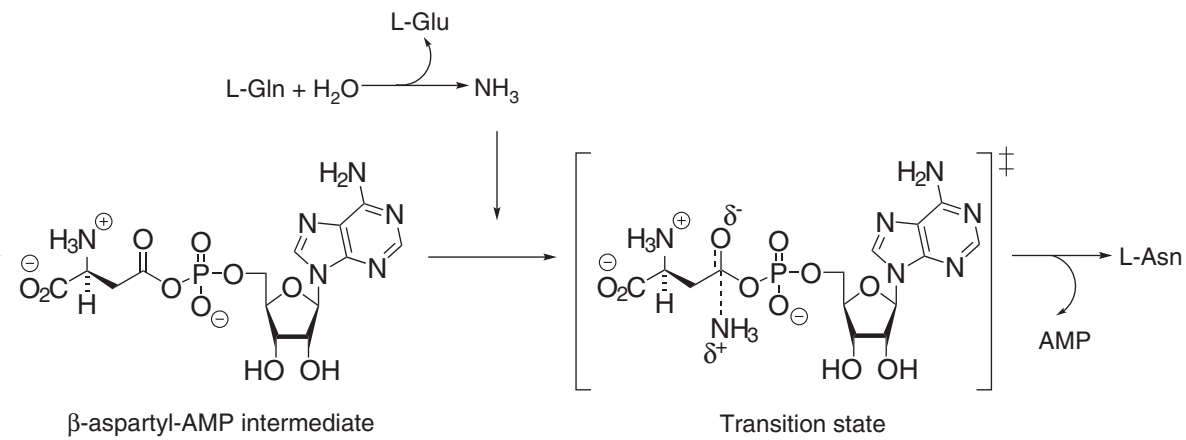

b

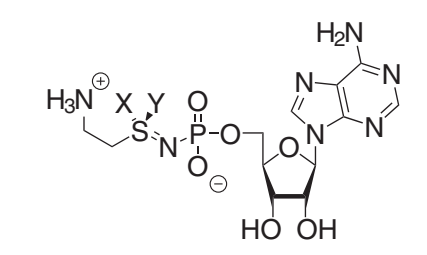

1a X $=\mathrm{CH}_{3}, \mathrm{Y}=\mathrm{O} ; \mathbf{1} \mathbf{b} \mathrm{X}=\mathrm{O}, \mathrm{Y}=\mathrm{CH}_{3}$

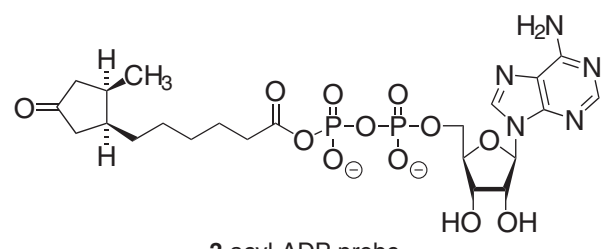

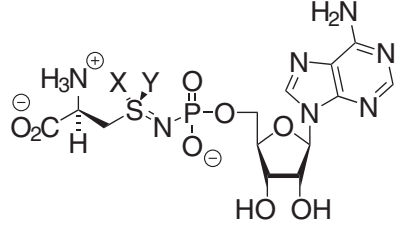

$2 \mathbf{a} X=\mathrm{CH}_{3}, \mathrm{Y}=\mathrm{O} ; \mathbf{2} \mathbf{b} \mathrm{X}=\mathrm{O}, \mathrm{Y}=\mathrm{CH}_{3}$

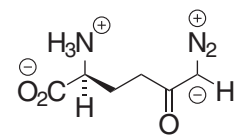

4 6-diazo-5-oxo-L-norleucine (DON)

Fig. 1 Catalytic mechanism of human ASNS and structures of compounds 1-4. a Overview of the chemical transformations catalyzed by ASNS showing the $\beta$-aspartyl-AMP intermediate and the transition state for its subsequent reaction with an ammonia molecule, which is released from L-glutamine in a separate glutaminase site. b Chemical structures for functionalized methylsulfoximines $\mathbf{1}$ and $\mathbf{2}$, activity-based probe $\mathbf{3}$ and 6-diazo-5-oxo-L-norleucine $\mathbf{4}$

energetics and intermolecular interactions lies outside the scope of this paper. Given that (i) the chemoproteomic probe 3 can target almost the full complement of human kinases ${ }^{38}$, and (ii) cells generally express about $40 \%$ of the human kinome ${ }^{39}$, a high level of selectivity is exhibited by this early-stage AMP-derived inhibitor at $10 \mu \mathrm{M}$ concentration. This finding therefore supports the idea that a second generation of specific ASNS inhibitors with more drug-like chemical structures ${ }^{40}$ can be developed.

The situation changes somewhat when chemoproteomic assays of HCT-116 lysates are performed in the presence of $100 \mu \mathrm{M}$ ASNS inhibitor 1 (Fig. 2 and Supplementary Data 1). For example, acylation by the probe 3 is suppressed by over $50 \%$ for 29 proteins (Fig. 2), and two- to three-fold increases in inhibition are observed for CMPK1, nicotinamide mononucleotide adenylyltransferase and the $\mathrm{ABC}$ transporters. Increased amounts of off-target binding to lysyl tRNA synthetase and other protein kinases in a dose-dependent fashion are also observed. Unexpectedly, suppression of Lys-466 acylation in human ASNS only increases to an extent of $72 \%$ when ASNS inhibitor $\mathbf{1}$ is present at $100 \mu \mathrm{M}$ concentration (Fig. 2). It is difficult to explain this relatively small increase in the assay although it may reflect changes in binding kinetics due to the increased extent of interaction of the inhibitor $\mathbf{1}$ with other proteins in the lysate. In addition, because a mixture of epimers $\mathbf{1} \mathbf{a}$ and $\mathbf{1 b}$ is used in the assay, the small change in binding to ASNS may reflect the fact that one of these diastereoisomers has much lower affinity for the enzyme, as discussed below. Finally, the affinity of ASNS inhibitor 1 for both ASS1 and splice isoform 2 of P43686 appears to be substantially decreased under these conditions (Fig. 2). Given that the reasons for this observation were not clear, we evaluated the ability of ASNS inhibitor 1 to bind to human ASS1 using in vitro kinetic measurements. Recombinant ASS1 was obtained by expression in Sf9 cells (Expression Systems, LLC), using the TEQC method for optimizing protein production, and purified by metal affinity chromatography (see Supplementary Information). Incubating the enzyme with substrates in the presence and absence of $10 \mu \mathrm{M}$ ASNS inhibitor 1 (see Supplementary Information) showed only weak inhibition on the basis of $\mathrm{MgPP}_{\mathrm{i}}$ formation (Supplementary Fig. 3). ASS1 activity was further decreased but not abolished when the ASNS inhibitor 1 was present at $100 \mu \mathrm{M}$ concentration. It is therefore possible that weak off-target interactions with ASS1 can take place in the cell.

Molecular structure of human ASNS. In order to determine the molecular basis for the binding selectivity of ASNS inhibitor 1 and to provide a firm basis for future, structure-based efforts to identify potent and selective ASNS inhibitors with simplified molecular scaffolds, we determined the high-resolution crystal structure of human ASNS by X-ray crystallography at $1.85 \AA$ resolution (Fig. 3). To date, only the structure of the glutaminedependent ASNS encoded by the $a s n B$ gene in Escherichia coli has been reported ${ }^{41}$. All efforts to obtain crystals of this and other bacterial ASNS homologs bound to small-molecules other than AMP have failed ${ }^{42}$. Moreover, kinetic studies have shown differences in the ability of ASNS inhibitor 2 (Fig. 1) to bind human ASNS and AS-B ${ }^{21,43}$. For our crystallization experiments, multimilligram amounts of highly active, recombinant, C-terminally His $_{10}$-tagged, human ASNS were obtained by expression in Sf9 cells ${ }^{44}$ using the TEQC method (see Supplementary Information $)^{45}$. The enzyme was initially purified by metal-affinity chromatography with subsequent removal of the C-terminal His $_{10}$-tag by digestion with the S219P variant of TEV protease ${ }^{46}$. The resulting sample of untagged ASNS was then reacted with 

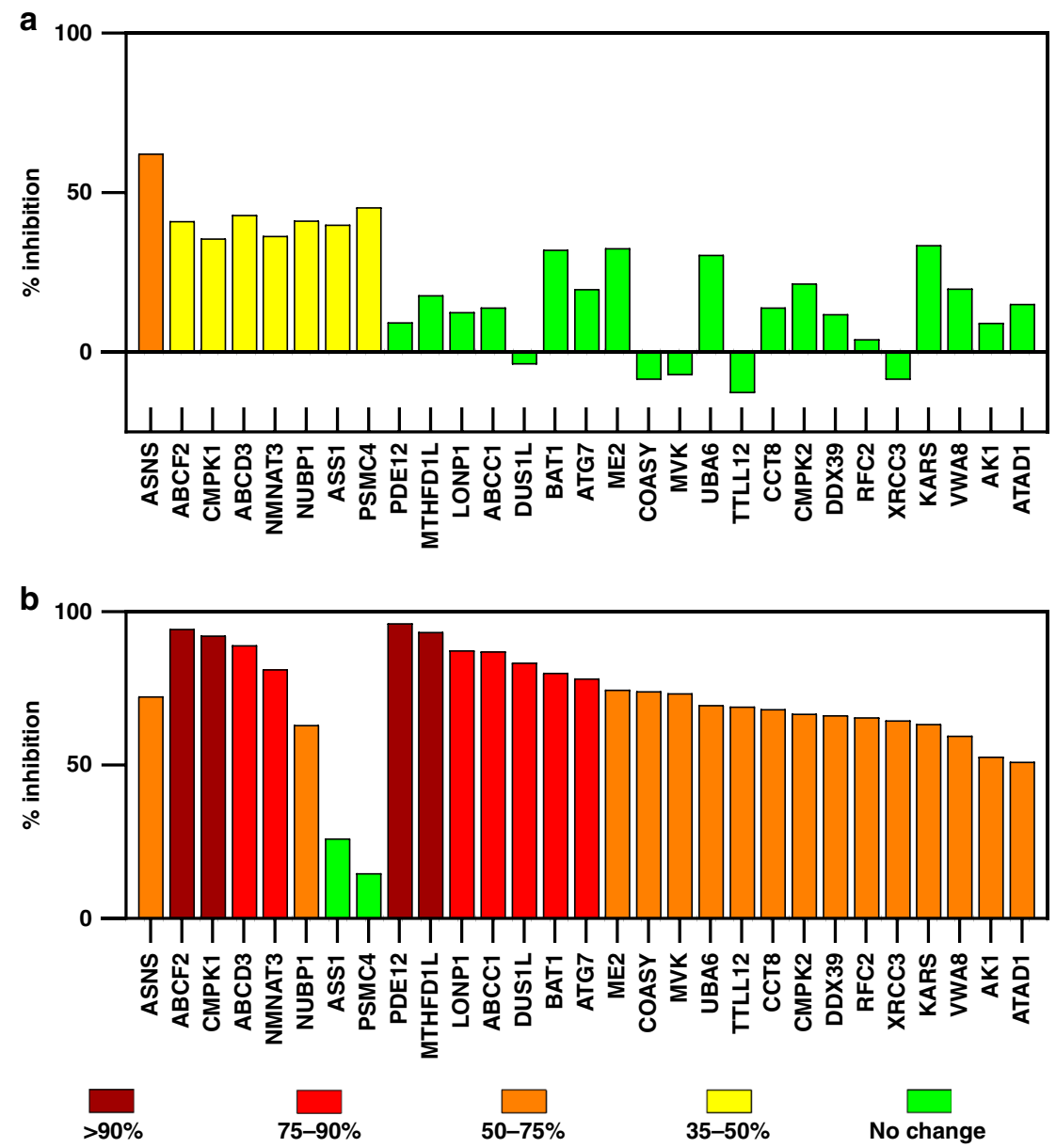

Fig. 2 Chemoproteomic Profiling of ASNS Inhibitor 1 Binding to Cellular ATPases. Percentage inhibition of lysine acylation by the reactive probe $\mathbf{3}$ in the presence of ASNS inhibitor $\mathbf{1}$ at $\mathbf{a} 10 \mu \mathrm{M}$ and $\mathbf{b} 100 \mu \mathrm{M}$ concentration. The inhibition values are color-coded based on suppression of lysine modification, as shown in the legend. Only inhibition levels greater than $50 \%$ are considered to be meaningful. Values lower than $35 \%$ fall in the range of sample to sample variability (CVs typically 20\%). Proteins were initially clustered based on inhibition values for lysates containing $10 \mu \mathrm{M}$ of inhibitor $\mathbf{1}$, and then ranked according to the extent of inhibition measured at $100 \mu \mathrm{M}$ concentration. Codes for proteins discussed in the text: ASNS-asparagine synthetase; NMNAT3-nicotinate-nucleotide adenylyltransferase; ASS1-argininosuccinate synthetase; KARS-lysyl-tRNA synthetase; CMPK1-UMP-CMP kinase 1; MVK-mevalonate kinase; CMPK2-UMP-CMP kinase 2; AK1-adenylate kinase isoenzyme 1. A complete set of protein codes and chemoproteomic profiling data is provided elsewhere (Supplementary Data 1)

DON (6-diazo-5-oxo-L-norleucine) ${ }^{47} \mathbf{4}$ (Fig. 1a) to modify the reactive thiolate of Cys-1 in the glutaminase active site of ASNS 48 . Mass spectrometric analysis of the as-purified and DON-modified protein showed the DON-modified form of human ASNS to be a homogeneous protein in which other cysteine residues in the protein had not been covalently modified (Supplementary Fig. 4; Supplementary Note 1). These mass spectrometric measurements also showed that the $\mathrm{N}$-terminal methionine residue of the recombinant enzyme had been correctly processed. Conditions were then identified that gave a single crystal of the DONmodified enzyme (Supplementary Fig. 5), which diffracted to $1.85 \AA$ resolution (Table 1 and Supplementary Fig. 6). The structure of human ASNS was solved by molecular replacement ${ }^{49}$ using $\mathrm{AS}-\mathrm{B}^{41}$ as a search model. Two molecules of DONmodified human ASNS were present in the asymmetric unit as a head-to-head dimer in which the two monomers were linked by a disulfide bond that likely forms during crystallization (Fig. 3a). As seen for the bacterial homolog, human ASNS is composed of two domains (Fig. 3b). Residues in the C-terminal (residues 203-560) synthetase domain $(41.6 \%$ identity) are more conserved than those in the N-terminal (residues 1-202) glutaminase domain (33.9\% identity) based on sequence comparisons of human ASNS and its homologs in a number of model organisms (Supplementary Fig. 7). The N-terminal domain of human ASNS possesses the typical sandwich-like $\alpha / \beta / \beta / \alpha$ topology present in $N$ terminal nucleophile (Ntn) amidotransferases ${ }^{50}$, such as GMP synthetase ${ }^{51}$, and glutamine PRPP amidotransferase ${ }^{52}$. A cisproline (Pro-60) linkage is present in the human enzyme identical to that in the structure of the bacterial homolog AS-B. Electron density for the DON-modified Cys- 1 side chain is clearly evident in each monomer (Fig. 3c). A hydrogen bond network, composed of the conserved residues Arg-48, Val-52, Asn-74, Gly-75, Glu-76, and Asp-96, which mediates substrate recognition and thioester stabilization in the hydrolysis reaction that produces ammonia, is also clearly defined ${ }^{53}$. This substrate-binding pocket is located at the interface of the two domains and is within $5 \AA$ of an absolutely conserved glutamate residue (Glu-414) in the C-terminal domain (Fig. 3d). After refinement of the protein and ligands, a single $12 \sigma$ peak remained in a pocket at the interface of the $\mathrm{N}$ and C-terminal domains on both chains. The site is surrounded by Tyr-78, Arg-416, Arg-245, and Val-417, and the peak was assigned as a chloride anion (Fig. 3b). The functional importance of this finding remains to be established for human ASNS, but plant asparagine synthetases are known to be activated by 

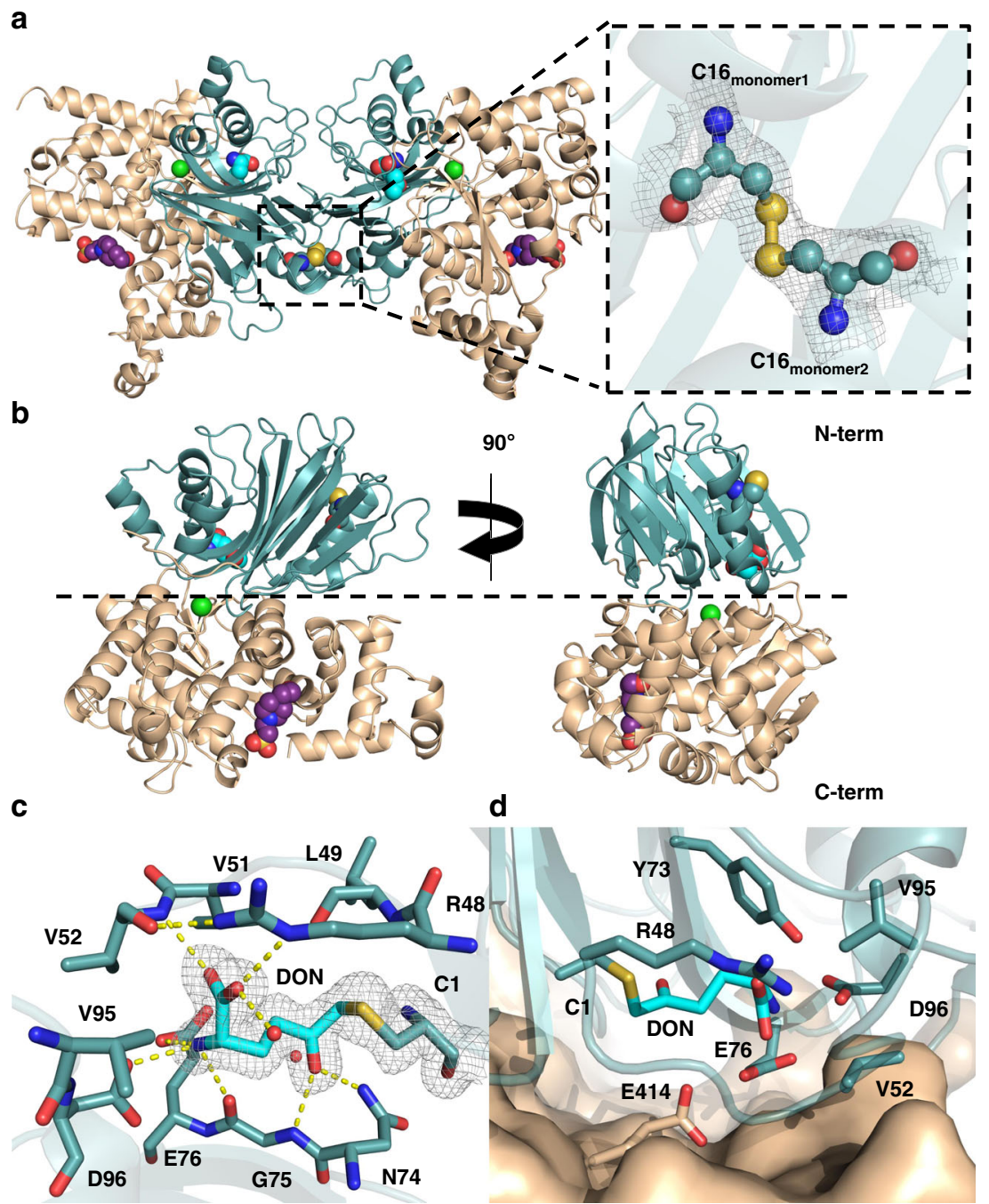

Fig. 3 X-ray crystal structure of human ASNS and the glutaminase active site. a Cartoon representation of the asymmetric unit of the human ASNS crystal structure and a close-up view of the disulfide bond connecting the N-terminal domains of the ASNS monomers and the electron density surrounding this region (gray mesh, contoured at $0.5 \sigma$ ). The $\mathrm{N}$ - and $\mathrm{C}$-terminal domains are colored teal and tan, respectively, and the atoms in the disulfide bond joining the monomers are rendered as spheres. Carbon atoms in the DON moiety and the HEPES molecule present in the synthetase active site are shown as cyan and purple spheres, respectively, and the bound chloride ion is drawn as a green sphere. Atom coloring scheme: C, cyan; N, blue; O, red; S, yellow. b Cartoon representation of the human ASNS monomer. The domain and atom coloring scheme is identical to that used in (a). c Close-up of DON-modified Cys1 showing the hydrogen bonding interactions between the DON moiety (cyan) and residues in the glutaminase active site. Electron density for DON, contoured at $0.5 \sigma$, is rendered as a mesh. $\mathbf{d}$ Location of the glutaminase site at the domain/domain interface of human ASNS. Residues are identified using standard one-letter codes and are numbered from the $\mathrm{N}$-terminal residue (Cys-1)

chloride ${ }^{54}$. Importantly for structure-based inhibitor discovery, the synthetase site in the C-terminal domain, which is composed of sixteen $\alpha$-helices and five $\beta$-strands, is well resolved (Fig. 3b). We also observed density consistent with a bound HEPES molecule from the crystallization buffer in this domain, which hydrogen bonds to the Asp-334 side chain and water molecules in a network that also involves conserved residues Asp-400 and Arg403 (Fig. 4a, b). Residues in the synthetase active sites of human ASNS and AS-B are highly conserved (Supplementary Fig. 7) except that Val-272 and Met-333 in the bacterial form of the enzyme are replaced by Ile-287 and Ile-347. Superimposing the human and bacterial structures confirms that the two synthetase active sites are almost identical (Fig. 4c and Supplementary Fig. 8). The Arg-403 side chain, however, adopts different conformations, presumably because AMP is not present in the synthetase site. Interesting structural differences in the intramolecular tunnel connecting the two active sites are also observed for human ASNS and AS-B (Supplementary Fig. 9).

Asparagine synthetase deficiency (ASD) linked variants. Having the crystal structure of human ASNS in hand offers an opportunity to map the locations of mutations in 15 residues that have been identified in patients with asparagine synthetase deficiency (ASD) (Fig. 5) ${ }^{2}$. Three of these mutational locations are in the Nterminal domain although, of these, only the Arg- 48 side chain is positioned such that it could interact directly with the L-glutamine substrate in the glutaminase active site. Substituting other amino acids in this position might therefore impact the steps leading to ammonia formation. The remaining sites, which are mainly located in the C-terminal domain, can be clustered into four groups (Supplementary Table 1). None of these residues, 


\section{Table 1 Crystallographic data collection and refinement} statistics

\section{Data collection}

\section{Beamline}

Wavelength $(\AA)$

Resolution range $(\AA)$

Space group

Unit cell $(a, b, c, \alpha, \beta, \gamma)$

Total reflections

Unique reflections

Multiplicity

Completeness (\%)

Mean I/ $\sigma(\mathrm{I})$

CC half

$R_{\text {merge }}$

$R_{\text {pim }}$

\section{Refinement}

$R_{\text {factor }}$

$R_{\text {free }}$

RMSD bonds $(\AA)$

RMSD angles $\left({ }^{\circ}\right)$

No. of non-H atoms

Protein

Ligands/metal ions

Water molecules

Protein residues

Average $B$ factors $\left(\AA^{2}\right)$

Main chain

Side chains

Ligands/metal ions

Water molecules

Ramachandran favored/

allowed (\%)

Molprobity score

1018 ( 2 chains; $A$ and $B$ )

\section{1}

39

30

31 on both chains)

\author{
Diamond i04 \\ 0.9795 \\ 33.65-1.85 (1.88-1.85) \\ $\mathrm{P} 2{ }_{1}$ \\ $64.7 \AA, 83.52 \AA, 110.29 \AA, 90^{\circ}$ \\ $90.65^{\circ}, 90^{\circ}$ \\ $339,772(16,876)$ \\ $100,002(4932)$ \\ $3.4(3.4)$ \\ $99.8(99.9)$ \\ $9.7(1.3)$ \\ $0.996(0.512)$ \\ $0.087(0.794)$ \\ $0.067(0.624)$
}

0.178
0.226
0.0119
1.488
8259
68
551
1018 (2 chains; $A$ and $B)$

97.02/2.78 (Phe399 is an outlier

0.87 , 100 th percentile $(N=12654$, $1.85 \pm 0.25 \AA)$

Crystallization conditions: Proplex E9, 0.2 M sodium chloride, $0.1 \mathrm{M}$ Hepes buffer $\mathrm{pH} 7.5$ and 12\% PEG 8000. Data collected on 10-07-1016 on MX12788-32 and processed with xia2 -3d pipeline. Data for the highest-resolution shell are given in parentheses. Note that $R_{\text {merge }}=\Sigma_{\text {hkl }} \Sigma$ $\left|I_{\mathrm{i}}-I_{\mathrm{m}}\right| / \Sigma_{\text {hk }} \Sigma_{\mathrm{i}} I_{\mathrm{i}}$ and $R_{\text {pim }}=\Sigma_{\text {hk }} \sqrt{1 / n}-1 \Sigma_{\mathrm{i}=1}\left|I_{\mathrm{i}}-I_{\mathrm{m}}\right| / \Sigma_{h k^{\prime}} \Sigma_{\mathrm{i}} I_{\mathrm{i}}$ where $I_{\mathrm{i}}$ and $I_{\mathrm{m}}$ are the observed intensity and mean intensity of related reflections, respectively.

however, seem to be positioned adjacent to L-aspartate or ATP in the synthetase active site. How these mutations exert their biological effects therefore remains unclear, although these might include altered catalytic activity due to changes in dynamical properties ${ }^{55}$, increased turnover or thermostability of the ASNS variant, or the interaction of ASNS with other proteins within the cell. Based on the ASNS structure we generated the T336I and F361V ASNS variants and assayed their glutamine-dependent activities relative to that of the WT enzyme by measuring $\mathrm{MgPP}_{\mathrm{i}}$ production (see Supplementary Information). The mutation at Thr-336, a Group IV residue (Supplementary Table 1), which is highly conserved across all the kingdoms (Supplementary Fig. 7), was chosen because it is located at the surface of the C-terminal synthetase active site. Similarly, Phe-361, a Group II residue (Supplementary Table 1), was of interest because it is located in the interior of the C-terminal domain at a distance of $7.2 \AA$ from the chloride-binding site. In addition, Phe- 361 is conserved in mammalian asparagine synthetases but is replaced by leucine in the glutamine-dependent plant and bacterial ASNS homologs (Supplementary Fig. 7). Although glutamine-dependent synthetase activity is almost abolished in the T336I ASNS variant, replacing Phe-361 by valine gives an ASNS variant showing a two-fold increase in activity relative to WT enzyme (Supplementary Fig. 10). It is possible that shrinking the Phe-366 side chain may impact structural packing within the C-terminal domain of the enzyme or binding of the chloride anion.

These findings support the idea that some of the ASD-linked changes might perturb asparagine-related metabolism. The apparent involvement of ASNS in neurological development implies that clinically useful ASNS inhibitors against metastasis must not cross the blood-brain barrier or be restricted to use in adults. Conversely, ASNS inhibitors capable of crossing the blood-brain barrier might have clinical utility in treating ASDlinked neurological disorders arising from ASNS variants with enhanced catalytic activity.

Computational studies of inhibitor binding to human ASNS. Kinetic measurements show that $\mathbf{1}$ is competitive with respect to ATP (the first substrate to bind in the pathway leading to asparagine formation) and can bind to the DON-modified form of human ASNS ${ }^{21}$. Both of these observations are consistent with the idea that ASNS inhibitor 1 binds within the synthetase active site of the enzyme (Fig. 4). Extensive crystallization trials, however, failed to yield crystals of the inhibitor bound to either DONmodified or WT human ASNS. Functionalized sulfoximines are stable to hydrolysis ${ }^{56}$, however, and the ${ }^{1} \mathrm{H}$ NMR spectrum of $\mathbf{1}$ is unchanged over a period of 19 days in the crystallization buffer. Given that epimers $\mathbf{1 a}$ and $\mathbf{1 b}$ cannot be separated by column chromatography, we carried out computational studies on models of human ASNS bound to either $\mathbf{1 a}$ or $\mathbf{1 b}$ in which Cys-1 was present as the unmodified amino acid (Fig. 6a). For these calculations, missing loops in the human ASNS structure, together with residues 534-546 located in the C-terminal tail, were built using the Modeller ${ }^{57}$ and Chimera ${ }^{58}$ software packages, and the conformational properties of these regions were validated with the Discrete Optimized Protein Energy protocol ${ }^{59}$. As a result, only the last 14 residues (547-560) of the enzyme were absent in this model (see Supplementary Information). We then positioned $\mathrm{MgPP}_{\mathrm{i}}$ within the ASNS synthetase site above a conserved pyrophosphate-binding loop ${ }^{60}$ in an identical orientation to that seen in the X-ray crystal structure of the evolutionarily related enzyme GMP synthetase ${ }^{51}$. $\mathrm{MgPP}_{\mathrm{i}}$ was included in the model structure because it is the last product released during turnover ${ }^{16}$ and is therefore present in the enzyme when ammonia reacts with the $\beta$-aspartyl-AMP intermediate. In silico docking ${ }^{61}$ was used to position $\beta$-aspartyl-AMP (Fig. 1a) and each of the epimers 1a and $\mathbf{1 b}$ into the $\mathrm{MgPP}_{\mathrm{i}} / \mathrm{ASNS}$ complex. The resulting three model complexes were next placed in a box of water molecules and subjected to molecular dynamics (MD) simulations (100 ns) (see Supplementary Information).

An extensive series of non-covalent interactions between $\beta$-aspartyl-AMP and the enzyme were observed in the equilibrated $\beta$-aspartyl-AMP/MgPP $/$ /ASNS complex (Supplementary Fig. 11a). For example, the phosphate moiety of this reactive intermediate forms an electrostatic interaction with the side chain of Lys-466, a conserved residue (Supplementary Fig. 7) that is essential for catalytic activity in AS- $\mathrm{B}^{62}$. In addition, the $2^{\prime}-\mathrm{OH}$ group on the ribose ring hydrogen bonds to the side chain of Ser362 , consistent with the fact that dATP is not a substrate for the enzyme. At the other end of the intermediate, the $\alpha$-amino group of $\beta$-aspartyl-AMP forms a salt bridge with the side chain of Asp367 and the $\alpha$-carboxylate interacts with Glu-364 via a bridging water molecule. To our knowledge, neither of these residues has been altered previously by site-directed mutagenesis even though both are conserved within known asparagine synthetases (Supplementary Fig. 7). A similar set of interactions to those seen in the $\beta$-aspartyl-AMP/MgPP $/$ ASNS complex were found in $\mathrm{MD}$ trajectories of the model $1 \mathrm{a} / \mathrm{MgPP}_{\mathrm{i}} / \mathrm{ASNS}$ and $\mathbf{1 b} / \mathrm{MgPP}_{\mathrm{i}} /$ ASNS complexes. Importantly for future inhibitor discovery 
a

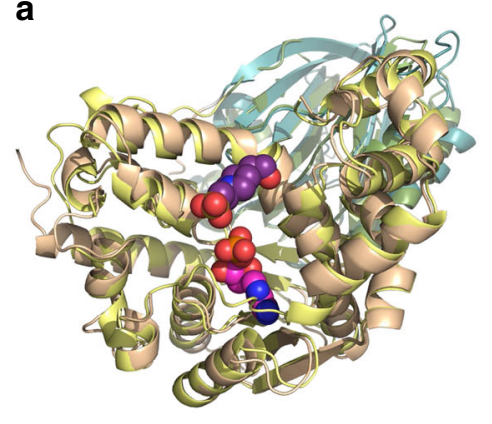

b
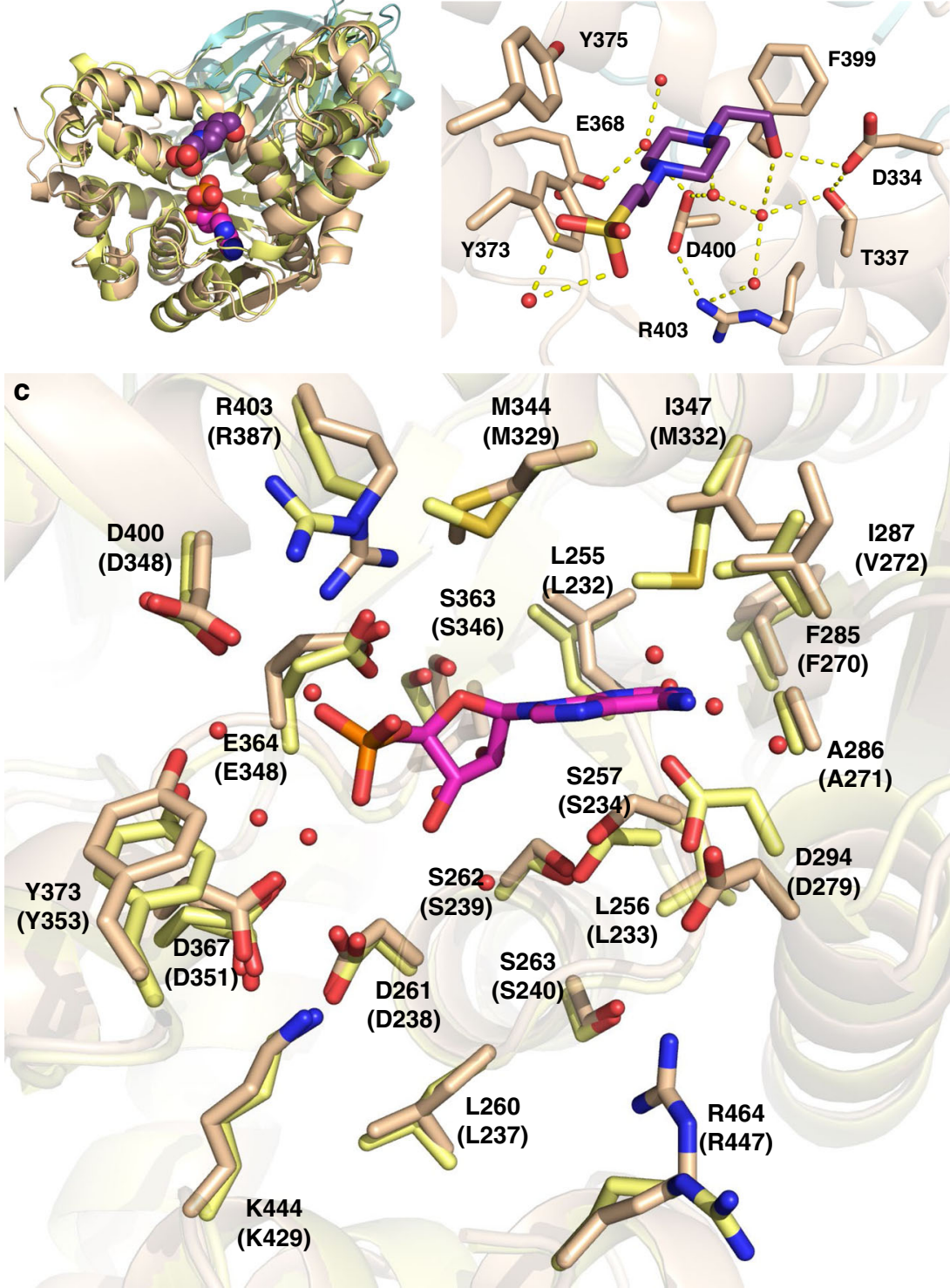

1347

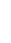

.

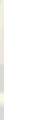




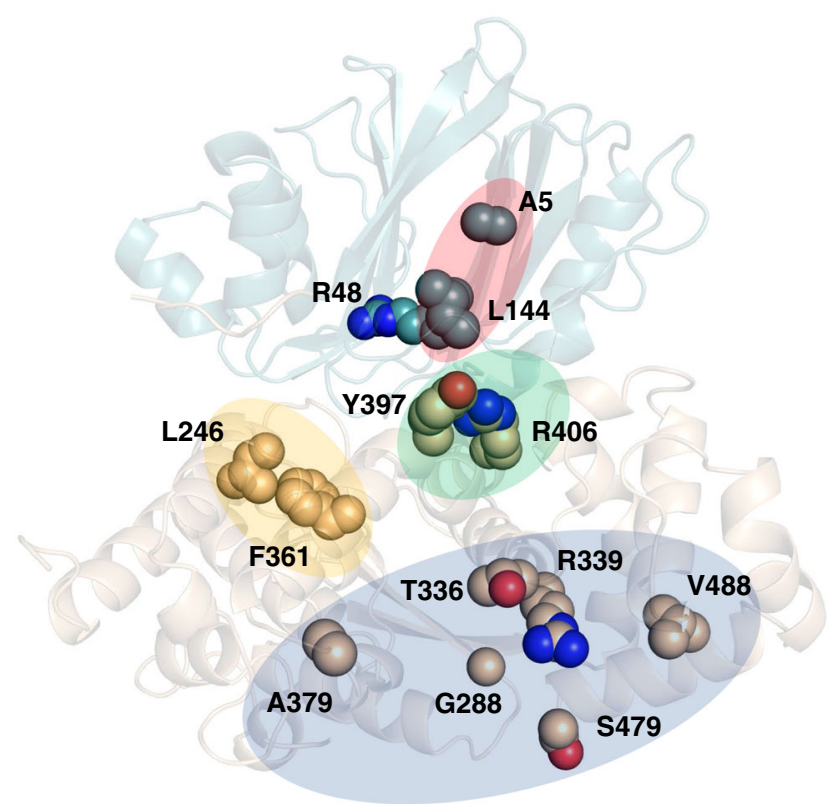

Fig. 5 Locations of mutated residues in human ASNS that are associated with asparagine synthetase deficiency. a Cartoon representation of the Xray crystal structure of human ASNS showing the locations of the 15 mutational sites (Ala-5, Arg-48, Leu-144, Leu-246, Gly-288, Thr-336, Arg339, Phe-361, Ala-379, Tyr-397, Arg-406, Ser-479, Val-488, Trp-540, and Arg-549) that have been identified in patients with asparagine synthetase deficiency. The side chains of mutated residues are rendered as spheres. Colored regions indicate sites that can be classified as Group I (red), Group II (yellow), Group III (green), and Group IV (blue) (Supplementary Table 1)

Glu-364 side chain was anticipated to weaken the binding of diastereoisomer $\mathbf{1 b}$ to the enzyme with little, or no, effect on diastereoisomer 1a. Assuming that $\mathbf{1 b}$ has greater affinity for the enzyme, as suggested by the FEP calculations, the mixture of epimers 1a and 1b was anticipated not to inhibit Glu-364 ASNS variants with nanomolar affinity. Similarly, removing the negatively charged Asp-367 side chain was expected to reduce the affinity of 1a rather than $\mathbf{1 b}$, meaning that the epimeric mixture $\mathbf{1 a}$ and $\mathbf{1 b}$ would exhibit the same level of inhibition when incubated with Asp-367 ASNS variants.

We expressed and purified ASNS variants in which Glu-364 was replaced by alanine (E364A) or glutamine (E364Q), and Asp367 was replaced by alanine (D367A) or asparagine (D367N). Kinetic assays monitoring $\mathrm{MgPP}_{\mathrm{i}}$ formation ${ }^{21,22}$ show that the E364A, E364Q, and D367A ASNS variants are inactive when incubated at $\mathrm{pH} 8.0$ with L-aspartate, ATP, and ammonium chloride as nitrogen source. Efforts to characterize the affinity of the ASNS inhibitor 1 for the three inactive ASNS variants using isothermal calorimetry have been unsuccessful, perhaps because of the slow off-rate of ASNS inhibitor 1 from the $E^{\star} I$ complex ${ }^{21}$. These data, however, reveal the importance of Glu-364 in binding and/or catalysis as predicted on the basis of the computational models. Moreover, the D367N ASNS variant exhibits reduced ammonia-dependent activity relative to that of WT enzyme when incubated at $\mathrm{pH} 8.0$ with L-aspartate, ATP and ammonium chloride (Supplementary Fig. 12). The D367N ASNS variant is also inhibited when incubated with $1 \mu \mathrm{M}$ ASNS inhibitor 1 although $\mathrm{MgPP}_{\mathrm{i}}$ production is stimulated at short reaction times under these conditions. In addition, inhibition of the D367N ASNS variant is seen at longer times than those at which the inhibitor abolishes ammonia-dependent activity of the WT enzyme (Supplementary Fig. 12). Nevertheless, slow-onset inhibition is still seen for the D367N ASNS variant after $200 \mathrm{sec}$, perhaps implying that removing the negative charge decreases the isomerization rate of the initial ASNS/inhibitor complex compared to that of WT enzyme. The altered inhibition kinetics support our prediction that epimer $\mathbf{1 b}$ has higher affinity for the synthetase site because of its interaction with the Glu-364 side chain.

Structure-based insights into ASNS inhibitor selectivity. The synthetase domain of human ASNS is evolutionarily related to similar AMP-forming domains in a large number of other prokaryotic and eukaryotic enzymes ${ }^{60}$. As part of trying to understand the pattern of binding selectivity observed in the chemoproteomic profiling assays (Fig. 2), we identified 128 AMP-forming domains in other protein structures with significant structural similarity to the synthetase domain (residues 222-533) (http://ekhidna2. biocenter.helsinki.fi/dali/) ${ }^{66}$ (Supplementary Data 2). Only 48 of the 128 structural neighbors are present in the human proteome, however, and crystal structures have been deposited for only 10 of these proteins (Supplementary Data 2). Almost all of these enzymes employ ATP, or the structurally similar co-factors SAM and $\mathrm{NAD}^{+}$, as substrates, with uroporphyrinogen-III synthase ${ }^{67}$ being an interesting exception. Importantly, transcriptome expression studies show that 47 of these 48 proteins are likely to be present in HCT-116 cell lysates (Supplementary Fig. 1), and we identified peptides from 10 of these proteins in our chemoproteomic profiling assay (Supplementary Data 1). Mechanistic considerations suggest that ASNS inhibitor 1 might exhibit off-target binding to glutamine-dependent $\mathrm{NAD}^{+}$synthetase ${ }^{68}, \mathrm{GMP}$ synthetase $^{32,51}$, argininosuccinate synthetase ${ }^{69}$, and FMN adenylyltransferase (NMAT1) ${ }^{70}$. Support for this idea is provided by the fact that these human enzymes have AMP-forming domains with the highest structural similarity to the synthetase domain of ASNS (Supplementary Data 2). Of these enzymes, as discussed above, ASNS inhibitor 1 exhibits off-target binding with ASS1 at $100 \mu \mathrm{M}$ concentration (Supplementary Fig. 3), but there is no evidence to indicate that such an interaction takes place with GMP synthetase in HCT-116 cell lysates (Supplementary Data 1). Tryptic peptides from the ATP-binding sites of glutamine-dependent $\mathrm{NAD}^{+}$synthetase and FMN adenylyltransferase, however, are not observed in the chemoproteomic profiling assays even though both proteins are expressed based on transcriptome data (Supplementary Fig. 1). As a result, the extent to which ASNS inhibitor 1 interacts with these two proteins is unresolved by these chemoproteomic profiling assays.

In an effort to place our findings on a structural foundation, we overlaid the conserved PP-loop motifs of our $\mathbf{1 b} / \mathrm{MgPP}_{\mathrm{i}} / \mathrm{ASNS}$ model complex and the X-ray crystal structures of human ASS1 and GMP synthetase (Fig. 7a). Even without extensive repositioning of residue side chains, these superimposed structures provide a qualitative picture of active site similarities and differences that might underlie the binding selectivity of ASNS inhibitor 1. All three enzymes share a common loop motif for binding $\mathrm{MgPP}_{\mathrm{i}}$ released during formation of the adenylated intermediate (Fig. 7a) and make very similar intermolecular interactions with the AMP moiety of the ASNS inhibitor $\mathbf{1 b}$ (Fig. 7b). Differences in inhibitor binding affinity seem to be associated with a cluster of negatively charged side chains (Fig. 4c) in the ASNS synthetase domain (Glu-364, Asp-367, and Glu-368) that bind the protonated amino group present in ASNS inhibitor 1 on the basis of computational modeling (Fig. 7c). This negatively charged pocket is absent in the active sites of argininosuccinate synthetase (Fig. 7d) and GMP synthetase (Fig. 7e). These data suggest that the residues Glu-364, Asp-367, and Glu-368 define the selectivity of ASNS inhibitor 1 towards human ASNS. If this is the case, second generation ASNS 
a

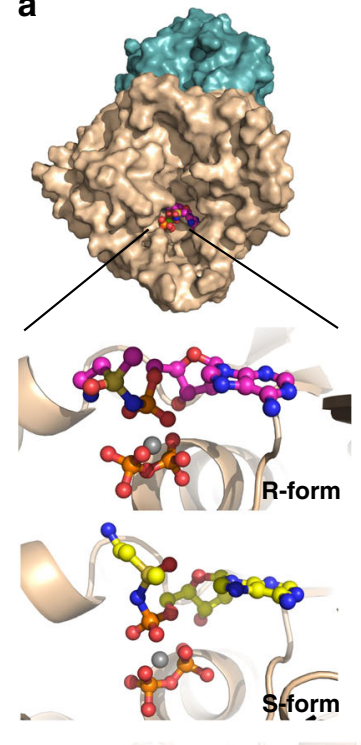

b

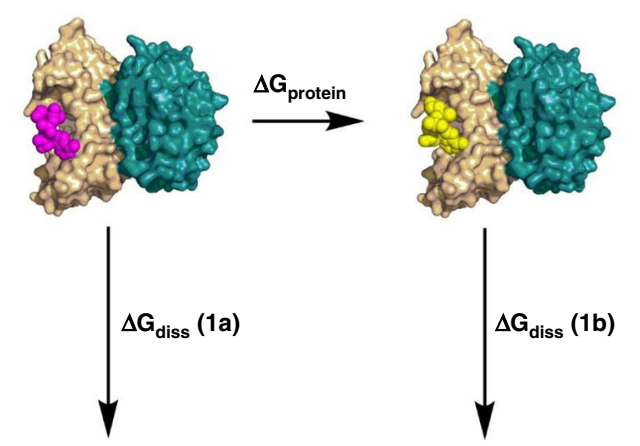

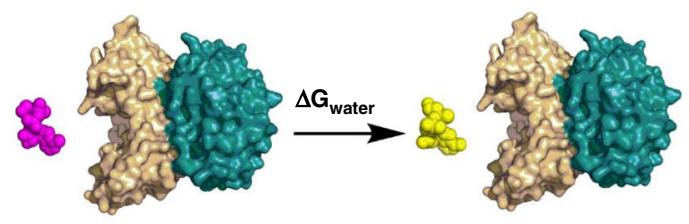

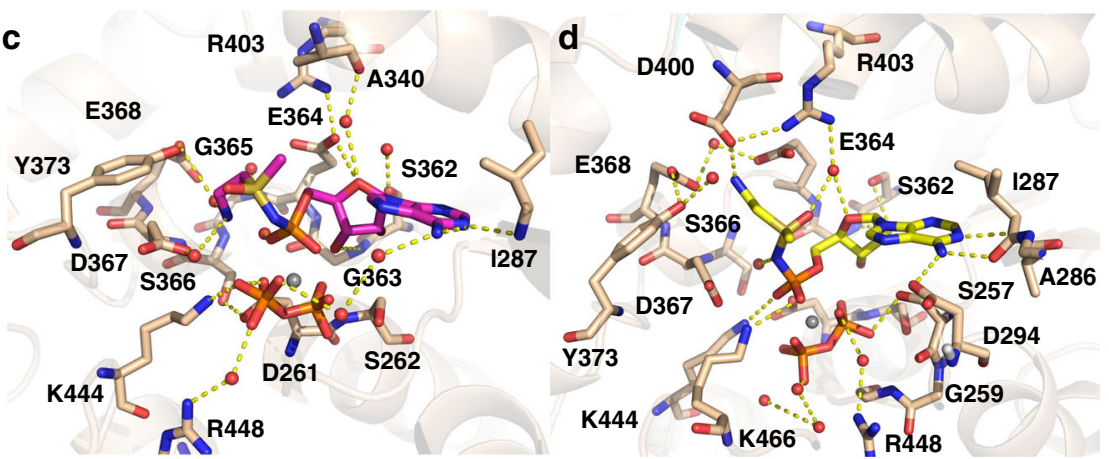

Fig. 6 Computational models of the functionalized methylsulfoximines $\mathbf{1 a}$ and $\mathbf{1 b}$ bound within the synthetase active site of the human ASNS/MgPP complex. a Surface representation of human ASNS showing the location of the putative inhibitor binding pocket within the synthetase active site. The Nand C-terminal domains of the enzyme are colored in teal and tan, respectively. Close-up views show the positions of the functionalized methylsulfoximines $\mathbf{1 a}$ (magenta) and $\mathbf{1 b}$ (yellow) relative to the bound inorganic pyrophosphate (orange) and $\mathrm{Mg}^{2+}$ (gray) ions in each model complex. b Thermodynamic cycle used to estimate the difference in binding free energy $\left(\Delta G_{\text {diss }}(\mathbf{1 a})-\Delta G_{\text {diss }}(\mathbf{1 b})\right.$ ) of the diastereoisomers $\mathbf{1 a}$ and $\mathbf{1 b}$ computed from $\Delta G_{\text {protein }}-\Delta G_{\text {water }}$ values obtained by free energy perturbation calculations. Both $\Delta G_{\text {diss }}(\mathbf{1 a})$ and $\Delta G_{\text {diss }}(\mathbf{1 b})$ have positive values since they describe dissociation of each ASNS/ligand complex. c Close-up of $\mathbf{1 a}$ showing the non-covalent interactions with synthetase active site residues and water molecules in the computational model. $\mathbf{d}$ Close-up of $\mathbf{1 b}$ showing the non-covalent interactions with synthetase active site residues and water molecules in the computational model

inhibitors must maintain the key electrostatic interactions with this negatively charged pocket if binding specificity is to be realized. In addition, given that the conserved residue Glu-364 is required for catalytic activity, it seems unlikely that resistance mutations could arise at this position in the ASNS synthetase active site.

\section{Discussion}

This work establishes the feasibility of obtaining ASNS inhibitors that exhibit considerable selectivity when present at low, or submicromolar concentrations in cells despite the existence of other ATP-utilizing enzymes possessing homologous catalytic domains to ASNS. Access to the X-ray structure of human ASNS, coupled with chemoproteomic profiling, has also allowed us to identify a cluster of negatively charged side chains in the ASNS synthetase domain (Glu-364, Asp-367, and Glu-368) that plays a key role in defining the binding selectivity of ASNS inhibitor 1 . These results will facilitate the discovery of new small-molecule ASNS inhibitors, which can be used (i) to probe the role of L-asparagine production in metastatic progression, and (ii) as agents to control either metastasis and/or tumor growth in animal-based experiments.

\section{Methods}

Chemical synthesis. Details of the synthetic procedures used to obtain the sulfoximine-based inhibitor 1 have been published elsewhere ${ }^{21}$.

NMR-based stability studies of ASNS inhibitor 1. A solution of $100 \mathrm{mM}$ sodium HEPES buffer, $\mathrm{pH} 7.5$, containing $200 \mathrm{mM} \mathrm{NaCl}(540 \mu \mathrm{L})$ was added to $10 \mathrm{mM}$ Tris-HCl buffer, $\mathrm{pH} 8$, containing $100 \mathrm{mM} \mathrm{NaCl}(420 \mu \mathrm{L})$ and the mixture was diluted with distilled water $(120 \mu \mathrm{L})$. An aliquot of this buffer solution $(480 \mu \mathrm{L})$ was then mixed with $50 \mathrm{mM}$ ASNS inhibitor 1 dissolved in water $(20 \mu \mathrm{L})$, and the resulting solution was transferred to an NMR tube together with a sealed capillary containing $5.5 \mathrm{mM}$ dimethylmalonate dissolved in $\mathrm{D}_{2} \mathrm{O}(60 \mu \mathrm{L})$. The final concentration of inhibitor 1 was $1.8 \mathrm{mM}$. ${ }^{1} \mathrm{H}$ NMR spectra were then recorded over a period of 19 days on an Avance-III HD $500 \mathrm{MHz}$ spectrometer. The water signal was suppressed using excitation sculpting with gradients ${ }^{71}$. No changes in the peaks arising from inhibitor 1 were observed during this time even though the sample was stored at room temperature.

Chemoproteomic profiling. The desthiobiotin-adenosine triphosphate-acylphosphate probe 3 (ATP probe) was synthesized as described previously ${ }^{24}$. An HCT116 cell pellet was lysed by sonication in lysis buffer $(50 \mathrm{mM}$ sodium HEPES, $\mathrm{pH}$ 7.5 , containing $150 \mathrm{mM} \mathrm{NaCl}, 0.1 \%(\mathrm{v} / \mathrm{v})$ Triton X-100 and phosphatase inhibitors 
a

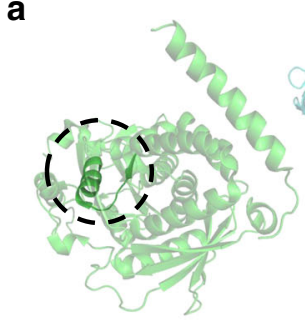

Argininosuccinate synthase

b

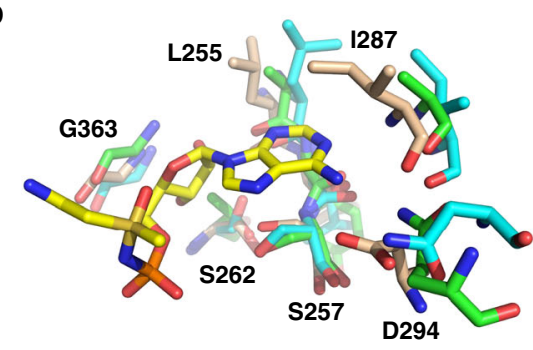

d

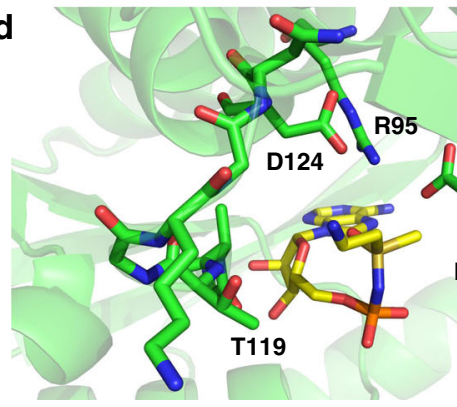

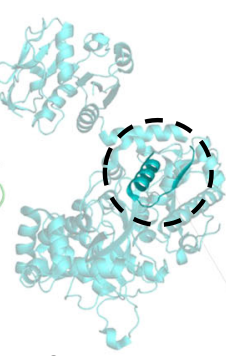

GMP synthase

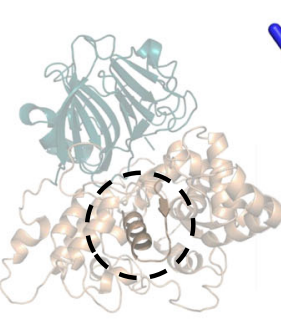

Asparagine synthetase

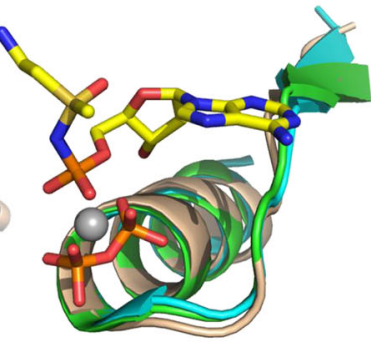

PP-loop

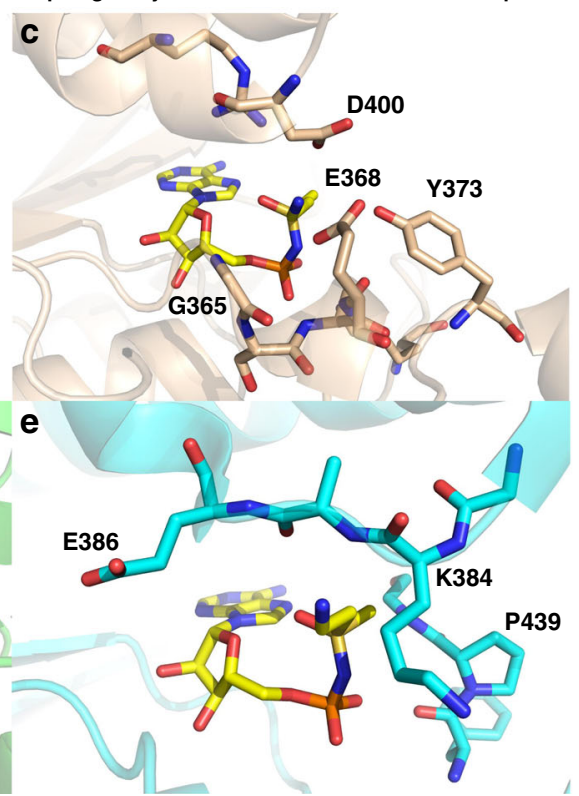

Fig. 7 Structural basis for the binding selectivity of ASNS inhibitor $\mathbf{1 b}$. a Alignment of the conserved SGGxD loops (PP-motifs) in argininosuccinate synthetase (2NZ2) ${ }^{69}$ (green), GMP synthetase (2VXO) ${ }^{32}$ (cyan) and the $\mathbf{1 b} / \mathrm{MgPP}_{\mathrm{i}} / \mathrm{ASNS}$ computational model (tan). Circles show the location of the PPmotif in the AMP-forming domain of the three enzymes. Carbon atoms in methylsulfoximine $\mathbf{1 b}$ are colored yellow. Color scheme: $\mathrm{N}$, blue; O, red; $\mathrm{P}$, orange; $\mathrm{Mg}$, gray. b Superimposition of the homologous AMP-binding sites in argininosuccinate synthetase (C: green), GMP synthetase (C: cyan) and the $\mathbf{1 b} / \mathrm{MgPP}_{\mathrm{i}} / \mathrm{ASNS}$ computational model ( $\mathrm{C}$ : tan) showing the similarity of residues in this region. ASNS residues are labeled using standard one-letter codes and are numbered from the $\mathrm{N}$-terminal residue (Cys-1). c Close-up of putative intermolecular interactions between the protonated amino group of $\mathbf{1 b}$ and human ASNS synthetase active site residues (C: tan). ASNS residues are labeled using standard one-letter codes and are numbered from the N-terminal residue (Cys-1). $\mathbf{d}$ Close-up of argininosuccinate synthetase residues (C: green) surrounding the protonated amino group of $\mathbf{1 b}$ assuming that the ASNS inhibitor binds to the enzyme in a similar pose to that modeled for human ASNS. Argininosuccinate synthetase residues are labeled using standard oneletter codes and are numbered from the X-ray crystal structure ${ }^{69}$. e Close-up of GMP synthetase residues (C: cyan) surrounding the protonated amino group of $\mathbf{1 b}$ assuming that the ASNS inhibitor binds to the enzyme in a similar pose to that modeled for human ASNS. GMP synthetase residues are labeled using standard one-letter codes and are numbered from the X-ray crystal structure ${ }^{32}$. The protein orientations in c-e are aligned to aid structural comparisons

[Cocktail II AG Scientific \#P-1518]). The samples were then centrifuged in an Eppendorf $5424 \mathrm{R}$ microcentrifuge at $16,200 \mathrm{xg}$ for $15 \mathrm{~min}$ at $4{ }^{\circ} \mathrm{C}$ and the supernatant collected for probe labeling. Five microliters ofthe sulfoximine-based inhibitor 1 was added from $100 \times$ stock solutions in dimethyl sulfoxide (DMSO) to $445 \mu \mathrm{L}$ of lysate in duplicate. DMSO $(5 \mu \mathrm{L})$ was added in control samples. After 15 min incubation, $50 \mu \mathrm{L}$ of a 10x aqueous solution of the ATP probe was added to each sample to give a final probe concentration of $5 \mu \mathrm{M}$, and samples were incubated with probe for an additional $10 \mathrm{~min}$. Samples were prepared for mass spectrometric (MS) analysis following standard procedures ${ }^{38}$. Briefly, probe-labeled lysates were denatured and reduced in $6 \mathrm{M}$ urea, $10 \mathrm{mM}$ dithiothreitol (DTT) at 65 ${ }^{\circ} \mathrm{C}$ for $15 \mathrm{~min}$ ), alkylated $\left(40 \mathrm{mM}\right.$ Iodoacetamide, $37^{\circ} \mathrm{C}, 30 \mathrm{~min}$ ), and gel filtered (Biorad Econo-Pac ${ }^{\circledR} 10 \mathrm{G}$ ) into $10 \mathrm{mM}$ ammonium bicarbonate, containing $2 \mathrm{M}$ urea and $5 \mathrm{mM}$ methionine. The desalted protein mixture was digested with trypsin $\left(0.015 \mathrm{mg} \mathrm{mL}^{-1}\right)$ for $1 \mathrm{hr}$ at $37^{\circ} \mathrm{C}$, and desthiobiotinylated peptides captured using $12.5 \mu \mathrm{L}$ high-capacity streptavidin resin (Thermo Scientific). Captured peptides were then washed extensively, and probe-labeled peptides eluted from the streptavidin beads using two $35-\mu \mathrm{L}$ washes of a $50 \%$ (v/v) $\mathrm{CH}_{3} \mathrm{CN} /$ water mixture containing $0.1 \%(\mathrm{v} / \mathrm{v})$ trifluoroacetic acid (TFA) at room temperature. The resulting samples were then analyzed on Thermo LTQ Velos ion trap mass spectrometers coupled with Agilent 1100 series micro-HPLC systems with autosamplers ${ }^{72}$. For signal extraction and quantitation, up to four ions were typically selected based on their presence, intensity, and correlation to the reference MS/MS spectrum. The resulting chromatographic peaks in each run were then integrated and the integrated peak areas used to determine \% inhibition values relative to control samples (Supplementary Data 1).

\section{Putative interaction of ASNS inhibitor 1 with UMP-CMP kinase 1 (CMPK1).}

Given that chemoproteomic profiling showed that ASNS inhibitor $\mathbf{1}$ binds human CMPK $1{ }^{36}$, which has a completely different fold to the synthetase domain of human ASNS, we built a model of how the ASNS inhibitor 1 might interact with the kinase, making the reasonable assumption that binding takes place within the ATP-binding site. Unfortunately, the X-ray crystal structure of human CMPK1 lacks a bound ligand ${ }^{73}$, and so we superimposed the ASNS inhibitor 1a on the bound ATP in the active site of the homologous enzyme in Dictyostelium discoideum $^{37}$ to obtain an initial model of the $1 \mathrm{a} / \mathrm{CMPK} 1$ complex (Supplementary Fig. 2). Preliminary MD simulations of this complex show that if the adenosyl group of 1a binds to the solvent accessible ATP-binding site then the protonated amino group of the inhibitor prefers to be solvated within the aqueous environment. These calculations also suggest that there are no specific interactions between the sulfoximine moiety and the protein. As a result, we speculate that both epimers $\mathbf{1 a}$ and $\mathbf{1 b}$ could bind to CMPK1. Additional studies, which lie outside the scope of this paper, will be needed to determine exactly how ASNS inhibitor $\mathbf{1}$ is bound by CMPK1. 
Expression and purification of recombinant human ASNS and the T336I, F361V, E364A, E364Q, D367A, and D367N ASNS variants. The open reading frame (ORF) of human ASNS containing a Tobacco Etch Virus protease (TEV protease $)^{74}$ site (ENLYFQS) followed by a C-terminal 10-histidine tag $\left(\mathrm{His}_{10}\right)$ was codon-optimized, synthesized, and sub-cloned into the EcoRV site of a pUC57 vector by GenScript (Piscataway, NJ), to give the pUC57-BamHI-hASNS-TEVHis $_{10}$-HindIII vector (Supplementary Data 3). The BamHI-HindIII DNA fragment from this vector was then sub-cloned into the same sites in a $\mathrm{pFL}$ vector ${ }^{75}$, yielding the pFL-hASNS-TEV-His 10 vector (pYT1215), which was then used to generate a recombinant baculovirus expressing C-terminally $\mathrm{His}_{10}$-tagged human ASNS following published protocols ${ }^{45}$. For large-scale expression, frozen stocks were generated and stored under liquid nitrogen. Sf9 cells were obtained from Expression Systems (Davis, CA), and were maintained in ESF921 medium (Expression Systems) at $27^{\circ} \mathrm{C}$ in shaker flasks. The expression of human ASNS in Sf9 cells was optimized using the TEQC method ${ }^{45}$. Briefly, a $1 \mathrm{~L}$ culture of Sf9 cells $\left(1.5 \times 10^{6}\right.$ cells $\mathrm{mL}^{-1}$ ) was infected with the baculovirus expressing recombinant human ASNS with MOI $=4.0$, the infected cells were then incubated at $27^{\circ} \mathrm{C}$ for $96 \mathrm{~h}$ before being harvested by centrifugation and frozen in liquid $\mathrm{N}_{2}$. The resulting pellet was then stored at $-80^{\circ} \mathrm{C}$ until lysed in $50 \mathrm{mM}$ Tris- $\mathrm{HCl}$ buffer, $\mathrm{pH} 8.0$, containing $500 \mathrm{mM} \mathrm{NaCl}$. After cell lysis and centrifugation, the supernatant was loaded onto a $5 \mathrm{~mL}$ GE HisTrap HP column (GE Healthcare) that was preequilibrated in $50 \mathrm{mM}$ Tris-HCl buffer, $\mathrm{pH} 8.0$, containing $500 \mathrm{mM} \mathrm{NaCl}$ using ÄKTAprime plus FPLC (GE Healthcare) and the C-terminally His $_{10}$-tagged, recombinant human ASNS was eluted from the column with increasing gradient $(0-100 \%)$ of buffer containing $50 \mathrm{mM}$ Tris- $\mathrm{HCl}, 500 \mathrm{mM}$ imidazole, $500 \mathrm{mM} \mathrm{NaCl}$, $\mathrm{pH}$ 8.0. The fractions containing human ASNS were confirmed by SDS-PAGE and combined. The resulting solution was exchanged to buffer containing $10 \mathrm{mM}$ Tris$\mathrm{HCl}$ buffer, $\mathrm{pH} 8.0$, containing $100 \mathrm{mM} \mathrm{NaCl}$ using a PD-10 column (GE Healthcare). Mass spectrometry on the as-purified intact protein confirmed that correctly processed, full-length enzyme had been purified. For crystallography, the C-terminal $\mathrm{His}_{10}$-tag was removed using the S219P variant of TEV protease (25:1 molar ratio $\mathrm{His}_{10}$-tagged human ASNS:TEV protease) and dialyzed at $4{ }^{\circ} \mathrm{C}$ overnight against $25 \mathrm{mM}$ Tris- $\mathrm{HCl}$ buffer, $\mathrm{pH} 8.0$, containing $250 \mathrm{mM} \mathrm{NaCl}$ and $5 \mathrm{mM}$ DTT. The sample was then flowed over the nickel column again to remove

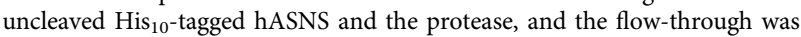
exchanged using a PD-10 column (GE Healthcare) into $10 \mathrm{mM}$ Tris- $\mathrm{HCl}$ buffer, $\mathrm{pH} 8.0$, containing $100 \mathrm{mM} \mathrm{NaCl}$ before the enzyme was concentrated to $6 \mathrm{mg} \mathrm{mL}^{-1}$

In a similar manner, codon-optimized DNAs (Supplementary Data 3) containing mutations encoding the T336I, F361V, E364A, E164Q, D367A, and D367N ASNS variants containing a TEV protease site ${ }^{74}$ followed by a C-terminal 10-histidine tag $\left(\mathrm{His}_{10}\right)$ were synthesized and introduced into pFL-hASNS-TEVHis $_{10}$ vector (pYT1215) by GenScript (Piscataway, NJ) to give vectors pYT1678 (T336I), pYT1690(F361V), pYT1668(E364A), pYT1667(E364Q), pYT1670 $(\mathrm{D} 367 \mathrm{~A})$, and $\mathrm{pYT} 1669(\mathrm{D} 367 \mathrm{~N})$. These transfer vectors were then used to generate baculoviruses that permitted the expression and purification of each human ASNS variant following the same protocol as that outlined above for the untagged, wildtype enzyme.

\section{Expression and purification of recombinant human argininosuccinate syn-} thetase (ASS1). The open reading frame (ORF) of human ASS containing an Nterminal $\mathrm{His}_{10}$ tag followed by a $3 \mathrm{C}$ protease ${ }^{76}$ site was codon-optimized, synthesized, and sub-cloned into the EcoRV site of the pUC57 vector by GenScript (Piscataway, NJ, USA) to give the pUC57-BamHI-hASS-HindIII plasmid (Supplementary Data 3). The BamHI-HindIII DNA fragment from each vector was then sub-cloned into the same sites in the pKL-10His-3C vector 77 to give the $\mathrm{PKL}$ 10His-3C-hASS (pYT1704) transfer vector. After generation of the baculovirus using this transfer vector, recombinant, N-terminally tagged WT human ASS1 was expressed in Sf9 insect cells using a similar protocol to that described above for WT human ASNS. Cells containing the recombinant enzyme were suspended in $50 \mathrm{mM}$ sodium phosphate buffer, $\mathrm{pH} 7.5$, containing $300 \mathrm{mM} \mathrm{NaCl}, 10 \mathrm{mM}$ imidazole, $5 \mathrm{mM}$ 2-mercaptoethanol, $0.01 \% \mathrm{NP}-40$ and $1 \mathrm{x}$ protease inhibitor cocktail (PI). After cell lysis at $4{ }^{\circ} \mathrm{C}$ for $30 \mathrm{~min}$, the resulting suspension was centrifuged $(35,000$ $\mathrm{rpm}$ ) at $4^{\circ} \mathrm{C}$ for $45 \mathrm{~min}$, and the supernatant was incubated with His-Select nickel affinity resin (Sigma) at $4^{\circ} \mathrm{C}$ for $1 \mathrm{~h}$. Unbound material was removed by washing the resin with lysis buffer without PI. The recombinant human ASS1 could then be eluted using lysis buffer without PI that contained $500 \mathrm{mM}$ imidazole. Elution fractions were concentrated (Vivaspin, $10000 \mathrm{MW}$ cutoff) to a volume of approximately $1 \mathrm{~mL}$ and dialyzed overnight at $4{ }^{\circ} \mathrm{C}$ against $50 \mathrm{mM}$ sodium HEPES buffer, $\mathrm{pH} 7.5$, containing $300 \mathrm{mM} \mathrm{NaCl}, 10 \%(\mathrm{v} / \mathrm{v})$ glycerol and $2 \mathrm{mM}$ DTT. The sample was then dialyzed at $4^{\circ} \mathrm{C}$ against $50 \mathrm{mM}$ sodium HEPES buffer, $\mathrm{pH} 7.5$, containing $300 \mathrm{mM} \mathrm{NaCl}, 10 \%(\mathrm{v} / \mathrm{v})$ glycerol and $2 \mathrm{mM}$ TCEP. The resulting sample, which had a final concentration of $0.4 \mathrm{mg} \mathrm{mL}^{-1}$, was then stored at $-80^{\circ} \mathrm{C}$.

Kinetic characterization of human ASS1. The activity of recombinant, WT human ASS1 was assayed by measuring the rate of inorganic pyrophosphate $\left(\mathrm{MgPP}_{\mathrm{i}}\right)$ production using an enzyme-coupled continuous assay (pyrophosphate reagent P7275, Sigma-Aldrich) ${ }^{78}$. In these experiments, assay mixtures contained $0.5 \mathrm{mM}$ ATP, $0.2 \mathrm{mM}$ L-aspartate, ASS1 $(4 \mu \mathrm{g})$, pyrophosphate reagent $(350 \mu \mathrm{L})$, and $2 \mathrm{mM} \mathrm{KCl}$ dissolved in $100 \mathrm{mM}$ Tris- $\mathrm{HCl}$ buffer, $\mathrm{pH} 7.5$, containing $5 \mathrm{mM}$ $\mathrm{MgCl}_{2}$ and ASNS inhibitor $\mathbf{1}$ (as a 1:1 mixture of diastereoisomers $\mathbf{1 a}$ and $\mathbf{1 b}$ ) at 0 $\mu \mathrm{M}, 10 \mu \mathrm{M}$, or $100 \mu \mathrm{M}$ concentration ( $1 \mathrm{~mL}$ total volume). Reactions were initiated at $37^{\circ} \mathrm{C}$ by the addition of $\mathrm{L}$-citrulline, to a final concentration of $0.2 \mathrm{mM}$, and $\mathrm{NADH}$ consumption was monitored spectrophotometrically at $340 \mathrm{~nm}$ over a period of 20 min using a Varian Cary ${ }^{\circledast} 50$ UV-visible spectrometer (Agilent Technologies) (Supplementary Fig. 3). All kinetic assays were performed in triplicate. A standard curve to convert absorbance units into $\mathrm{MgPP}_{\mathrm{i}}$ concentration was constructed using known amounts of $\mathrm{MgPP}_{\mathrm{i}}$ dissolved in $100 \mathrm{mM}$ Tris- $\mathrm{HCl}$ buffer, $\mathrm{pH} 7.5$, containing $5 \mathrm{mM} \mathrm{MgCl}, 0.2 \mathrm{mM}$ L-aspartate, $0.2 \mathrm{mM}$ L-citrulline, and $2 \mathrm{mM} \mathrm{KCl}$. The standard curve was unaffected by the presence of $100 \mu \mathrm{M}$ ASNS inhibitor 1.

Crystallization and structure solution of human ASNS. Prior to crystallization, recombinant human ASNS $\left(140 \mu \mathrm{L}\right.$ of a $6 \mathrm{mg} \mathrm{mL}^{-1}$ solution in $10 \mathrm{mM}$ Tris- $\mathrm{HCl}$ buffer, $\mathrm{pH} 8.0$, containing $100 \mathrm{mM} \mathrm{NaCl}$ ) was incubated with $20 \mathrm{mM}$ 6-diazo-5oxo-L-norleucine (DON) $(20 \mu \mathrm{L})$ at room temperature for $45 \mathrm{~min}$ to give the DON-modified form of the enzyme (Supplementary Fig. 4) ${ }^{79}$. A solution of $20 \mathrm{mM}$ sodium pyrophosphate $(20 \mu \mathrm{L})$ was then added to the DON-modified human ASNS to give a stock solution. Automated sitting-drop crystallization trials were carried out on a Hydra II Plus 1 crystallization robot using a 1:1 ratio of protein to reservoir solution. A single crystal grew in conditions containing $0.2 \mathrm{M} \mathrm{NaCl}, 0.1 \mathrm{M}$ sodium HEPES buffer, $\mathrm{pH}$ 7.5, and 12\% (w/v) PEG 8000 (ProPlex HT-96, Molecular Dimensions) at $17^{\circ} \mathrm{C}$ after a period of 3 weeks (Supplementary Fig. 5). This crystal was harvested after 5 weeks and flash cooled using liquid nitrogen in a cryoprotectant comprising the crystallization conditions, plus an additional $25 \%(\mathrm{w} / \mathrm{v})$ ethylene glycol. Diffraction data were collected at Diamond Light Source beamline i 04 at $100 \mathrm{~K}$, using a wavelength of $0.9795 \AA$. Data were processed using the $3 \mathrm{~d}$ module of the Xia 2 pipeline ${ }^{80}$ revealing that the crystal belonged to the space group $\mathrm{P} 2{ }_{1}$ with unit cell dimensions of $\mathrm{a}=64.7 \AA, \mathrm{b}=83.52 \AA$, and $\mathrm{c}=110.29 \AA$. Molecular replacement was carried out in PHASER ${ }^{81}$, from within the CCP $4 \mathrm{i}^{82}$ package, using the glutamine-dependent asparagine synthetase from Escherichia coli (PDB:1CT9) ${ }^{41}$ as a search model. Refinement of the initial model was carried out in an iterative manner using REFMAC5 (ref. ${ }^{83}$ ) combined with manual rebuilding in $\operatorname{Coot}^{84}$. The resulting model, which contained 2 molecules of DONmodified, human ASNS per asymmetric unit, 551 molecules of water, and 2 molecules of HEPES, was refined to $1.85 \AA$ resolution (Supplementary Fig. 6). The MolProbity server ${ }^{85}$ was used to validate the structure, with the Ramachandran plot showing that one residue (Phe-399) is a Ramachandran outlier on both chains. The cognate residue in AS-B is also an outlier, suggesting that an unusual backbone geometry is conserved in this area of the enzyme. All other residues were in favorable or allowed areas of the Ramachandran plot. Coordinates have been deposited in the Protein Data Bank under accession number 6GQ3.

Kinetic characterization of ASD-linked human ASNS variants. The specific activity of the T336I and F361V ASD-linked ASNS variants was determined using the EnzChek ${ }^{\mathrm{TM}}$ Pyrophosphate Assay (Molecular Probes). Briefly, reaction was initiated by addition of $0.1 \mu \mathrm{M}$ enzyme to a reaction mixture containing $150 \mathrm{mM}$ $\mathrm{NaCl}, 10 \mathrm{mM} \mathrm{MgCl}, 1 \mathrm{mM}$ DTT, $10 \mathrm{mM}$ L-glutamine, $10 \mathrm{mM}$ L-aspartate, $5 \mathrm{mM}$ ATP, $0.2 \mathrm{mM}$ MESG, $1 \mathrm{U} \mathrm{mL}^{-1}$ purine nucleoside phosphorylase, and $0.03 \mathrm{U} \mathrm{mL}^{-1}$ inorganic pyrophosphatase at $37^{\circ} \mathrm{C}$ in $100 \mathrm{mM}$ EPPS buffer, $\mathrm{pH}$ 8.0. The activity was monitored by measuring the absorption change at $360 \mathrm{~nm}$ using a Varian Cary 50 UV-visible spectrometer (Agilent Technologies). A standard curve was determined using standard $\mathrm{MgPP}_{\mathrm{i}}$ solution diluted in a buffer solution of $100 \mathrm{mM}$ EPPS, $\mathrm{pH} 8.0$, containing $150 \mathrm{mM} \mathrm{NaCl}, 10 \mathrm{mM} \mathrm{MgCl}, 1 \mathrm{mM} \mathrm{DTT}, 10 \mathrm{mM}$ L-glutamine, $10 \mathrm{mM}$ L-aspartate, $5 \mathrm{mM}$ ATP, $0.2 \mathrm{mM}$ MESG, $1 \mathrm{U} \mathrm{mL}^{-1}$ purine nucleoside phosphorylase, and $0.03 \mathrm{U} \mathrm{mL}^{-1}$ inorganic pyrophosphatase at $37^{\circ} \mathrm{C}$. The percentage activity of each variant was normalized against that of WT human ASNS (Supplementary Fig. 10).

Molecular dynamics simulations of human ASNS, its complexes with the $\beta$ aspartyl-AMP intermediate, and with the functionalized methylsulfoximines $\mathbf{1 a}$ and $\mathbf{1 b}$. The X-ray crystallographic coordinates of DON-modified human ASNS were used to build the initial model of the enzyme for simulations of the enzyme/ inhibitor complexes. Segments of missing residues and side chains were built using Modeller $^{57}$ and the Chimera GUI ${ }^{58}$. The conformational properties of these regions were validated with the Discrete Optimized Protein Energy (DOPE) protocol ${ }^{59}$. All amino acid residues introduced into the X-ray crystal structure were geometry optimized with all other atoms constrained to their crystallographic coordinates. This model was then energy minimized following standard protocols to remove bad contacts, before being further refined using the AMBER software suite ${ }^{86}$. Thus the complex was solvated in a truncated octahedral box $(98 \times 98 \times 98 \AA)$ of TIP3P 87 water molecules together with eight $\mathrm{Na}^{+}$ions. After assignment of ff14SB force field ${ }^{88}$ parameters, the system was energy minimized while constraining the positions of the non-hydrogen protein atoms $\left(500 \mathrm{kcal} \mathrm{mol}^{-1} \AA^{-2}\right)$. The restraining force constant was then reduced $\left(10 \mathrm{kcal} \mathrm{mol}^{-1} \AA^{-2}\right)$, and the system slowly heated to $300 \mathrm{~K}$ and equilibrated over a period of $2.4 \mathrm{~ns}$ in the NVE ensemble with periodic boundary conditions. In these simulations, restraints were placed on hydrogen atoms that were not involved in hydrogen bonds using the 
SHAKE $^{89}$ algorithm. The temperature of the system in these equilibration simulations was controlled using a Langevin thermostat ${ }^{90}$. A final equilibration was carried out in an NPT ensemble ( $300 \mathrm{~K}$ and $1 \mathrm{~atm})$ for $15 \mathrm{~ns}$. All MD simulations employed a non-bonded cutoff of $12 \AA$.

This structure was then used as the basis for modeling the $\mathbf{1 a} / \mathrm{MgPP}_{\mathrm{i}} / \mathrm{ASNS}, \mathbf{1 b} /$ $\mathrm{MgPP}_{\mathrm{i}} / \mathrm{ASNS}$, and $\beta$-aspartyl-AMP/MgPP $/$ /ASNS complexes by docking the appropriate ligand into the synthetase active site. The initial positions of the ligands were selected using procedures that we have described elsewhere ${ }^{21}$, with inorganic pyrophosphate being positioned in an identical orientation above the SGGxD loop to that observed in the X-ray crystal structure of GMP synthetase (PDB: 1GPM) ${ }^{51}$ Each of these three structures and the free enzyme were then placed within an orthorhombic box of explicit TIP3P water molecules. The box size was chosen so that there was a $10 \AA$ buffer distance in each dimension from any protein atom. These four model systems were energy minimized, until a gradient threshold of $25 \mathrm{kcal} \mathrm{mol}^{-1} \AA^{-1}$ was attained, and then equilibrated at $300 \mathrm{~K}$ using a series of short MD simulations. The resulting models were then subject to $100 \mathrm{~ns}$ of MD simulation in the NPT ensemble at a temperature of $300 \mathrm{~K}$ and a pressure of $1 \mathrm{~atm}$ using the DESMOND ${ }^{91}$ software package with the OPLS-2005 all-atom force field ${ }^{92}$. In these simulations, hydrogen atoms were constrained using the SHAKE algorithm ${ }^{89}$, and long-range electrostatic energies were computed by particle mesh Ewald ${ }^{93}$ with a short-range cutoff of $12 \AA$ for short-range Coulombic interactions. Structures were sampled from the trajectory at $20 \mathrm{ps}$ intervals (5000 frames per simulation) analyzed using standard methods.

\section{Free energy perturbation (FEP/REST2) estimates of the relative binding} affinities of $\mathbf{1 a}$ and $\mathbf{1 b}$. FEP/REST2 calculations ${ }^{63,64,94}$ were performed to obtain estimates of the free energy difference between the functionalized methylsulfoximines $\mathbf{1 a}$ and $\mathbf{1 b}$ within the synthetase active site of human ASNS using the algorithms implemented in the DESMOND ${ }^{38}$ software package and describing atoms in $\mathbf{1 a}$ and $\mathbf{1 b}$ with the OPLS-2005 all-atom force field ${ }^{39}$. Thus, the optimized model of the $1 \mathrm{a} / \mathrm{MgPP}_{\mathrm{i}} / \mathrm{ASNS}$ complex was placed within an orthorhombic box (12 ̊ buffer distance in each dimension from any protein atom) of explicit TIP3P water molecules with sufficient $\mathrm{Na}^{+}$ions to neutralize the charge of the system. Changing the configuration about the sulfur atom in the ligand was accomplished using $100 \mathrm{~ns} \mathrm{MD}$ simulations at each of $12 \lambda$ values $(1.0,0.92,0.83,0.75,0.67,0.58$, $0.42,0.33,0.25,0.17,0.08,0.0$ ) with the heavy atoms of the ligand (apart from those of the adenosine moiety) being selected for enhanced sampling, as described elsewhere ${ }^{63,64,94}$. These calculations gave an estimate for $\Delta G_{\text {protein }}$ of $-10 \pm 2.1 \mathrm{~kJ}$ $\mathrm{mol}^{-1}$ based on the Bennett acceptance ratio ${ }^{95}$. Following a similar protocol, FEP/ REST2 calculations were performed to obtain estimates of the free energy difference between the functionalized methylsulfoximines $\mathbf{1 a}(\lambda=0)$ and $\mathbf{1 b}(\lambda=1)$ when solvated in a box of explicit TIP3P water molecules. In these latter set of calculations, the initial conformation of 1 a was identical to that present in the model of the $1 \mathrm{a} / \mathrm{MgPP} / \mathrm{ASNS}$ complex. These calculations gave an estimate for $\Delta G_{\text {water }}$ of $-0.20 \pm 0.17 \mathrm{~kJ} \mathrm{~mol}^{-1}$. As a result, the difference in binding free energies of the two ligands is estimated to be $-10.2 \mathrm{~kJ} \mathrm{~mol}^{-1}$, based on a standard thermodynamic cycle (Fig. 5b). As a result, one can write the following expression:

$$
\Delta G_{\text {diss }}(1 \mathbf{a})-\Delta G_{\text {diss }}(1 \mathbf{b})=-2.303 R T \log _{10}\left[\frac{K_{\mathrm{d}}(1 \mathbf{b})}{K_{\mathrm{d}}(1 \mathbf{a})}\right]
$$

When $R=8.314 \mathrm{~J} \mathrm{~mol}^{-1} \mathrm{~K}^{-1}$ and $T=298.15 \mathrm{~K}$, this yields a value of $\frac{K_{\mathrm{d}}(1 \mathbf{b})}{K_{\mathrm{d}}(\mathbf{a})}=63$.

\section{Examining predictions of the computational models by site-directed muta-} genesis. The activity of WT human ASNS and four ASNS variants (E364A, E364Q, D367A, and D367N) was assayed by measuring the rate of $\mathrm{MgPP}_{\mathrm{i}}$ production using a continuous assay employing the EnzChek ${ }^{\mathrm{TM}}$ Pyrophosphate Assay (Molecular Probes) as described in detail elsewhere ${ }^{96}$. In these experiments, assay mixtures contained $0.5 \mathrm{mM}$ ATP, $5 \mathrm{mM}$ L-aspartate $0.01 \mathrm{U} \mathrm{mL}^{-1}$ nucleoside phosphorylase, $3 \times 10^{-4} \mathrm{U} \mathrm{mL}^{-1}$ inorganic phosphatase, and $100 \mathrm{mM} \mathrm{NH}_{4} \mathrm{Cl}$ dissolved in $100 \mathrm{mM}$ EPPS buffer, $\mathrm{pH} 8.0$, containing $10 \mathrm{mM} \mathrm{MgCl}_{2}$ and either $0 \mu \mathrm{M}$ or $1 \mu \mathrm{M}$ ASNS inhibitor $\mathbf{1}$ (as a 1:1 mixture of epimers $1 \mathbf{a}$ and $\mathbf{1 b})(1 \mathrm{~mL}$ total volume). Reactions were initiated at $25^{\circ} \mathrm{C}$ by the addition of recombinant, WT human ASNS $(4 \mu \mathrm{g})$, and 2-amino-6-mercapto-7-methylpurine production was then monitored spectrophotometrically at $360 \mathrm{~nm}$ over a period of $10 \mathrm{~min}$. All kinetic assays were performed in triplicate. Identical assay conditions were employed in studies of the D367N ASNS variant except that L-aspartate was present at a final concentration of $50 \mathrm{mM}$ and reactions were initiated by the addition of recombinant enzyme $(40 \mu \mathrm{g})$. A standard curve to convert absorbance units into $\mathrm{MgPP}_{\mathrm{i}}$ concentration was constructed using known amounts of $\mathrm{MgPP}_{\mathrm{i}}$ dissolved in $50 \mathrm{mM}$ EPPS buffer, $\mathrm{pH} 8.0$, containing $50 \mathrm{mM} \mathrm{L}$-aspartate, $200 \mathrm{mM} \mathrm{NaCl}$ and $2 \mathrm{mM}$ TCEP. The standard curve was unaffected by the presence of up to $10 \mu \mathrm{M}$ ASNS inhibitor 1.

General note. The $\mathrm{pH}$ of all buffer solutions used in the following experimental procedures was adjusted by the addition of either aq. $\mathrm{HCl}$ or aq. $\mathrm{NaOH}$.

Statistics and reproducibility. The primary statistical analysis in the chemoproteomic profiling measurements is a determination of the significance of inhibition using the Student $t$-test. All datapoints for which 1 inhibits modification of the
ATP-binding site by the reactive probe 3 to an extent that is greater than $35 \%$ are considered significant if $p<0.04$. Control CVs are calculated using the expression [(control std. deviation)/(average control signal) $]{ }^{*} 100 \%$. Estimates of the errors in the free energy calculations are based on the Bennett acceptance ratio. Values for percentage activities or steady-state kinetic parameters are calculated (mean \pm standard deviation) from triplicate measurements.

Reporting summary. Further information on research design is available in the Nature Research Reporting Summary linked to this article.

\section{Data availability}

Atomic coordinates and structure factors for recombinant, DON-modified human ASNS have been deposited in the Protein Data Bank with accession number 6GQ3. Coordinates for the computational models of the $1 \mathrm{a} / \mathrm{MgPP}_{\mathrm{i}} / \mathrm{ASNS}, \mathbf{1} \mathbf{b} / \mathrm{MgPP}_{\mathrm{i}} / \mathrm{ASNS}$ and $\beta$-aspartyl$\mathrm{AMP} / \mathrm{MgPP}_{\mathrm{i}} / \mathrm{ASNS}$ complexes, MD simulation trajectories and $\mathrm{I} / \mathrm{O}$ files for the free energy calculations, and raw data for protein purification and kinetic assays are available from Professor Nigel Richards (RichardsN14@cardiff.ac.uk) on request. Requests for plasmids and other reagents needed to obtain the ASNS variants used in this study should be sent to Professor Yuichiro Takagi (ytakagi@iu.edu). Raw data for the chemoproteomic profiling experiments can be obtained by contacting Dr. Tyzoon Nomanbhoy (tyzoonn@ACTIVX.com).

Received: 6 September 2018 Accepted: 21 August 2019 Published online: 17 September 2019

\section{References}

1. Richards, N. G. J. \& Schuster, S. M. Mechanistic issues in asparagine synthetase catalysis. Adv. Enzymol. Relat. Areas Mol. Biol. 72, 145-198 (1998).

2. Lomelino, C. L., Andrig, J. T., McKenna, R. \& Kilberg, M. S. Asparagine synthetase: function, structure, and role in disease. J. Biol. Chem. 292, 19952-19958 (2017).

3. Ruzzo, E. K. et al. Deficiency of asparagine synthetase causes congenital microcephaly and a progressive form of encephalopathy. Neuron $\mathbf{8 0}, 429-441$ (2013).

4. Hettmer, S. et al. Functional genomic screening reveals asparagine dependence as a metabolic vulnerability in sarcoma. eLife 4, e09436 (2015).

5. Hettmer, S. et al. Sarcomas induced in discrete subsets of prospectively isolated skeletal muscle cells. Proc. Natl. Acad. Sci. USA 108, 20002-20007 (2011).

6. Son, J. et al. Glutamine supports pancreatic cancer growth through a KRASregulated metabolic pathway. Nature 496, 101-105 (2013).

7. Pui, C.-H., Robison, L. L. \& Look, A. T. Acute lymphoblastic leukemia. Lancet 371, 1030-1043 (2008).

8. Yang, H. et al. Down-regulation of asparagine synthetase induces cell cycle arrest and inhibits cell proliferation of breast cancer. Chem. Biol. Drug Des. 84, 578-584 (2014).

9. Xu, Y., Ly, F., Zhu, X., Wu, Y. \& Shen, X. Loss of asparagine synthetase suppresses the growth of human lung cancer cells by arresting cell cycle at G0/ G1 phase. Cancer Gene Ther. 23, 287-294 (2016).

10. Sircar, K. et al. Integrative molecular profiling reveals asparagine synthetase is a target in castration-resistant prostate cancer. Am. J. Pathol. 180, 895-903 (2012).

11. Du, F. et al. SOX12 promotes colorectal cancer cell proliferation and metastasis by regulating asparagine synthesis. Cell Death Dis. 10, 239 (2019).

12. Knott, S. E. et al. Asparagine bioavailability governs metathesis in a model of breast cancer. Nature 554, 378-381 (2018).

13. Richards, N. G. J. \& Kilberg, M. S. Asparagine synthetase chemotherapy. Annu. Rev. Biochem. 75, 629-654 (2006).

14. Cooney, D. A., Jones, M. T., Milman, H. A., Young, D. M. \& Jayaram, H. N. Regulators of the metabolism of L-asparagine: A search for endogenous inhibitors. Int. J. Biochem. 11, 519-539 (1980)

15. Boehlein, S. K., Richards, N. G. J., Walworth, E. S. \& Schuster, S. M. Arginine30 and asparagine- 74 have functional roles in the glutamine dependent activities of Escherichia coli asparagine synthetase B. J. Biol. Chem. 269, 26789-26795 (1994)

16. Tesson, A. R., Soper, T. S., Ciustea, M. \& Richards, N. G. J. Re-visiting the steady-state kinetic mechanism of glutamine-dependent asparagine synthetase from Escherichia coli. Arch. Biochem. Biophys. 413, 23-31 (2003).

17. Boehlein, S. K. et al. Kinetic mechanism of Escherichia coli asparagine synthetase B. Biochemistry 38, 13230-13238 (1998).

18. Koroniak, L., Ciustea, M., Gutierrez, J. A. \& Richards, N. G. J. Synthesis and characterization of an $\mathrm{N}$-acylsulfonamide inhibitor of human asparagine synthetase. Org. Lett. 5, 2033-2036 (2003). 
19. Lücking, U. Sulfoximines: a neglected opportunity in medicinal chemistry. Angew. Chem. Int. Ed. 52, 9399-9408 (2013).

20. Hiratake, J. Enzyme inhibitors as chemical tools to study enzyme catalysis: rational design, synthesis, and applications. Chem. Rec. 5, 209-228 (2005).

21. Ikeuchi, H. et al. A human asparagine synthetase inhibitor kills asparaginaseresistant MOLT-4 cells. Bioorg. Med. Chem. 20, 5915-5927 (2012).

22. Gutierrez, J. A. et al. An inhibitor of human asparagine synthetase suppresses proliferation of an L-asparaginase resistant leukemia cell line. Chem. Biol. 13, 1339-1347 (2006).

23. Rosenblum, J. S., Nomanbhoy, T. K. \& Kozarich, J. W. Functional interrogation of kinases and other nucleotide-binding proteins. FEBS Lett. 587, 1870-1877 (2013).

24. Patricelli, M. P. et al. Functional interrogation of the kinome using nucleotide acyl phosphates. Biochemistry 46, 350-358 (2007).

25. Liston, D. R. \& Davis, M. Clinically relevant concentrations of anticancer drugs: a guide for nonclinical studies. Clin. Cancer Res. 23, 3489-3498 (2017).

26. Rajput, A. et al. Characterization of HCT116 human colon cancer cells in an orthotopic model. J. Surg. Res. 147, 276-281 (2006).

27. Morrison, J. F. \& Walsh, C. T. The behavior and significance of slowbinding enzyme inhibitors. Adv. Enzymol. Relat. Areas Mol. Biol. 61, 201-301 (1988).

28. Tonge, P. J. Drug-target kinetics in drug discovery. ACS Neurosci. 9, 29-39 (2018).

29. Roionova, I. A. et al. Structure of M. tuberculosis nicotinate mononucleotide adenylyltransferase. J. Biol. Chem. 290, 7693-7706 (2015).

30. Husson, A., Brasse-Lagnel, C., Fairand, A., Renouf, S. \& Lavoinne, A. Argininosuccinate synthetase from the urea cycle to the citrulline-NO cycle. Eur. J. Biochem. 270, 1887-1899 (2003).

31. Izard, T. The crystal structures of phosphopantetheine adenylyltransferase with bound substrates reveal the enzyme's catalytic mechanism. J. Mol. Biol. 315, 487-495 (2002)

32. Welin, M. et al. Substrate specificity and oligomerization of human GMP synthetase. J. Mol. Biol. 425, 4323-4333 (2013).

33. Sekine, S., Nureki, O., Shimada, A., Vassylyev, D. G. \& Yokoyama, S. Structural basis for anticodon recognition by discriminating glutamyl-tRNA synthetase. Nat. Struct. Mol. Biol. 8, 203-206 (2001).

34. Koizumi, M., Hiratake, J., Nakatsu, T., Kato, H. \& Oda, J. Potent transition state analogue inhibitor of Escherichia coli asparagine synthetase A. J. Am. Chem. Soc. 121, 5799-5800 (1999).

35. Hinchman, S. K., Henikoff, S. \& Schuster, S. M. A relationship between asparagine synthetase A and aspartyl tRNA synthetase. J. Biol. Chem. 267, 144-149 (1992).

36. Van Rompay, A. R., Johansson, M. \& Karlsson, A. Phosphorylation of deoxycytidine analog monophosphates by UMP-CMP kinase: Molecular characterization of the human enzyme. Mol. Pharmacol. 56, 562-569 (1999).

37. Schlichtling, I. \& Reinstein, J. pH influences fluoride coordination number of the $\mathrm{AlF}_{\mathrm{x}}$ phosphoryl transfer transition state analog. Nat. Struct. Mol. Biol. 6 721-723 (1999).

38. Patricelli, M. P. et al. In situ kinase profiling reveals functionally relevant properties of native kinases. Chem. Biol. 18, 699-710 (2011).

39. Manning, G., Whyte, D. B., Martinez, R., Hunter, T. \& Sudarsanam, S. The protein kinase complement of the human genome. Science 298, 1912-1934 (2002).

40. Lipinski, C. A., Lombardo, F., Dominy, B. W. \& Feeney, P. J. Experimental and computational approaches to estimate solubility and permeability in drug discovery and development settings. Adv. Drug Deliv. Rev. 46, 3-26 (2001).

41. Larsen, T. M. et al. Three-dimensional structure of Escherichia coli asparagine synthetase B: a short journey from substrate to product. Biochemistry 38, 16146-16157 (1999).

42. Fresquet, V., Thoden, J. B., Holden, H. M. \& Raushel, F. M. Kinetic mechanism of asparagine synthetase from Vibrio cholerae. Bioorg. Chem. 32, 63-75 (2004)

43. Boehlein, S. K. et al. Characterization of inhibitors acting at the synthetase site of Escherichia coli asparagine synthetase B. Biochemistry 40, 11168-11175 (2001).

44. Ciustea, M., Gutierrez, J. A., Abbatiello, S. E., Eyler, J. R. \& Richards, N. G. J. Efficient expression, purification and characterization of C-terminally tagged, recombinant human asparagine synthetase. Arch. Biochem. Biophys. 440, 18-27 (2005)

45. Imasaki, T., Wenzel, S., Yamada, K., Bryant, M. L. \& Takagi, Y. Titer estimation for quality control (TEQC) method: a practical approach for optimal production of protein complexes using the baculovirus expression system. PLoS ONE 13, e0195356 (2018).

46. Waugh, D. S. An overview of enzymatic reagents for the removal of affinity tags. Prot. Expr. Purif. 80, 283-293 (2011).

47. Handschumacher, R. E., Bates, C. J., Chang, P. K., Andrews, A. T. \& Fischer, G. A. 5-Diazo-4-oxo-L-norleucine: reactive asparagine analog with biological specificity. Science 161, 62-63 (1968).
48. Zalkin, H. \& Smith, J. L. Enzymes utilizing glutamine as an amide donor. Adv. Enzymol. Relat. Areas Mol. Biol. 72, 87-144 (1998).

49. Vagin, A. \& Teplyakov, A. Molecular replacement with MOLREP. Acta Crystallogr. Sect. D: Biol. Crystallogr. 66, 22-25 (2010).

50. Brannigan, J. A. et al. A protein catalytic framework with an Nterminal nucleophile is capable of self-activation. Nature 378, 416-419 (1995).

51. Tesmer, J. G., Klem, T. J., Deras, M. L., Davisson, V. J. \& Smith, J. L. The crystal structure of GMP synthetase reveals a novel catalytic triad and is a structural paradigm for two enzyme families. Nat. Struct. Biol. 3, 74-86 (1996).

52. Krahn, J. M. et al. Coupled formation of an amidotransferase interdomain ammonia channel and a phosphoribosyltransferase active site. Biochemistry 36, 11061-11068 (1997)

53. Boehlein, S. K., Rosa-Rodriguez, J. G., Schuster, S. M. \& Richards, N. G. J. Catalytic activity of the $\mathrm{N}$-terminal domain of Escherichia coli asparagine synthetase B can be reengineered by single-point mutation. J. Am. Chem. Soc 119, 5785-5791 (1997).

54. Rognes, S. E. Anion regulation of lupin asparagine synthetase: chloride activation of the glutamine-utilizing reactions. Phytochemistry 19, 2287-2293 (1980).

55. Klinman, J. P. Dynamically achieved active site precision in enzyme catalysis. Acc. Chem. Res. 48, 449-456 (2014).

56. Lin, Y. et al. Green and efficient synthesis of $\mathrm{N}$-sulfenyl sulfoximines in water. ACS Sustain. Chem. Eng. 6, 13644-13649 (2018).

57. Šali, A. \& Blundell, T. L. Comparative protein modelling by satisfaction of spatial restraints. J. Mol. Biol. 234, 799-815 (1993).

58. Pettersen, E. F. et al. UCSF chimera - a visualization system for exploratory research and analysis. J. Comput. Chem. 25, 1605-1612 (2004).

59. Shen, M.-Y. \& Šali, A. Statistical potential for assessment and prediction of protein structures. Prot. Sci. 15, 2507-2524 (2006).

60. Bork, P. \& Koonin, E. V. A P-loop-like motif in a widespread ATPpyrophosphatase domain: implications for the evolution of sequence motifs and enzyme activity. Protein.: Struct. Funct. Genet 20, 347-355 (1994).

61. Friesner, R. A. et al. Glide: a new approach for rapid, accurate docking and scoring. 1. Method and assessment of docking accuracy. J. Med. Chem. 47, 1739-1749 (2004)

62. Ikeuchi, H., Meyer, M. E., Ding, Y., Hiratake, J. \& Richards, N. G. J. A critical electrostatic interaction mediates inhibitor recognition by human asparagine synthetase. Bioorg. Med. Chem. 17, 6641-6650 (2009).

63. Wang, L., Friesner, R. A. \& Berne, B. J. Replica exchange with solute scaling: a more efficient version of replica exchange with solute tempering (REST2). J. Phys. Chem. B 115, 9431-9438 (2011)

64. Wang, L., Berne, B. J. \& Friesner, R. A. On achieving high accuracy and reliability in the calculation of relative protein-ligand binding affinities. Proc. Natl. Acad. Sci. USA 109, 1937-1942 (2012).

65. Abel, R., Wang, L., Harder, E. D., Berne, B. J. \& Friesner, R. A. Advancing drug discovery through enhanced free energy calculations. Acc. Chem. Res. 50, 1625-1632 (2017)

66. Holm, L. \& Sander, C. Dali: a network tool for protein structure comparison. Trends Biochem. Sci. 20, 478-480 (1995).

67. Mathews, M. A. et al. Crystal structure of human uroporphyrin III synthase. EMBO J. 20, 5832-5839 (2001).

68. LaRonde-LeBlanc, N., Resto, M. \& Gerratana, B. Regulation of active site coupling in glutamine-dependent $\mathrm{NAD}^{+}$synthetase. Nat. Struct. Mol. Biol. 16, 421-429 (2009).

69. Karlberg, T. et al. Structure of human argininosuccinate synthetase. Acta Crystallogr. Sect. D: Biol. Crystallogr. 64, 279-286 (2008).

70. Huerta, C., Borek, D., Machius, M., Grishin, N. V. \& Zhang, H. Structure and mechanism of a eukaryotic FMN adenylyltransferase. J. Mol. Biol. 389, 388-400 (2009).

71. Hwang, T.-L. \& Shaka, A. J. Water suppression that works. Excitation sculpting using arbitrary waveforms and pulsed field gradients. J. Magn Reson. A 112, 275-279 (1995)

72. Nordin, B. E. et al. ATP Acyl phosphate reactivity reveals native conformations of Hsp90 paralogs and inhibitor target engagement. Biochemistry 54, 3024-3036 (2015).

73. Sekulic, N., Ort, S., Konrad, M. \& Lavie, A. Substrate-induced conformational changes in human UMP/CMP kinase. J. Biol. Chem. 279, 33882-32889 (2004)

74. Kapust, R. B. et al. Tobacco etch virus protease: mechanism of autolysis and rational design of stable mutants with wild-type catalytic proficiency. Protein Eng. 14, 993-1000 (2001).

75. Fitzgerald, D. J. et al. Protein complex expression by using multigene baculoviral vectors. Nat. Methods 3, 1021-1032 (2006).

76. $\mathrm{Xu}, \mathrm{H}$. et al. A simplified method to remove fusion tags from a xylanase of Bacillus sp. HBP8 with HRV 3C protease. Enzym. Microb. Technol. 123, 15-20 (2019). 
77. Rogers, C. M. et al. Yeast Hrq1 shares structural and functional homology with the disease-linked human RecQ4 helicase. Nucl. Acids Res. 49, 5217-5230 (2017).

78. O'Brien, W. E. A continuous spectrophotometric assay for argininosuccinate synthetase based on pyrophosphate formation. Anal. Biochem. 76, 423-430 (1976).

79. Jayaram, H. N., Cooney, D. A., Milman, H. A., Homan, E. R. \& Rosenbluth, R. J. DON, CONV and DONV. 1. Inhibition of L-asparagine synthetase in vitro. Biochem. Pharmacol. 25, 1571-1582 (1976).

80. Winter, G. xia2: an expert system for macromolecular crystallography data reduction. J. Appl. Crystallogr. 43, 186-190 (2010).

81. Winn, M. D. et al. Overview of the CCP4 suite and current developments. Acta Crystallogr. Sect. D. Biol. Crystallogr. 67, 235-242 (2011).

82. McCoy, A. J. et al. Phaser crystallographic software. J. Appl. Crystallogr. 40 658-674 (2007).

83. Murshudov, G. N. et al. REFMAC5 for the refinement of macromolecular crystal structures. Acta Crystallogr. Sect. D. Biol. Crystallogr. 67, 355-367 (2011).

84. Emsley, P., Lohkamp, B., Scott, W. G. \& Cowtan, K. Features and development of Coot. Acta Crystallogr. Sect. D. Biol. Crystallogr. 66, 486-501 (2010).

85. Chen, V. B. et al. MolProbity: All-atom structure validation for macromolecular crystallography. Acta Crystallogr. Sect. D. Biol. Crystallogr. 66, 12-21 (2010).

86. Case, D. A. et al. The amber biomolecular simulation programs. J. Comput. Chem. 26, 1668-1688 (2005).

87. Jorgensen, W. L., Chandrasekhar, J., Madura, J. D., Impey, R. W. \& Klein, M. L. Comparison of simple potential functions for simulating liquid water. J. Chem. Phys. 79, 926-935 (1983).

88. Maier, J. A. et al. ff14SB: improving the accuracy of protein side chain and backbone parameters from ff99SB. J. Chem. Theory Comput. 11, 3696-3713 (2015).

89. Ryckaert, J.-P., Ciccotti, G. \& Berendsen, H. J. C. Numerical integration of the Cartesian equations of motion of a system with constraints: molecular dynamics simulations of n-alkanes. J. Comput. Phys. 23, 327-341 (1977).

90. Berendsen, H. J. C., Postma, J. P. M., van Gunsteren, W. F., DiNola, A. \& Haak, J. R. Molecular dynamics with coupling to an external bath. J. Chem. Phys. 81, 3684-3690 (1984).

91. Bowers, K. J. et al. Scalable algorithms for molecular dynamics simulations on commodity clusters. Proc. ACM/IEEE Conf. Supercomputing (SC06) (2006).

92. Banks, J. L. et al. Integrated modeling program, applied chemical theory (IMPACT). J. Comput. Chem. 26, 1752-1780 (2005).

93. Darden, T., York, D. \& Pedersen, L. Particle mesh Ewald: an $N \cdot \log (N)$ method for ewald sums in large systems. J. Chem. Phys. 98, 10089-10092 (1993).

94. Liu, P., Kim, B., Friesner, R. A. \& Berne, B. J. Replica exchange with solute tempering: a method for sampling biological systems in explicit water. Proc. Natl. Acad. Sci. USA 102, 13749-13754 (2005).

95. Bennett, C. H. Efficient estimation of free energy differences from monte carlo data. J. Comput. Phys. 22, 245-268 (1976).

96. Upson, R. H., Haugland, R. P., Malekzadeh, M. N. \& Haugland, R. P. A spectrophotometric method to measure enzymatic activity in reactions that generate inorganic pyrophosphate. Anal. Biochem. 243, 41-45 (1996).

\section{Acknowledgements}

We are grateful to Dr. H. Ikeuchi and Professor J. Hiratake (Kyoto) for generously providing samples of the human ASNS inhibitor 1 used in the functional proteomics experiments. We thank the Diamond Light Source for beam time allocation and beam line staff for assistance with data collection. Mass spectrometric characterizations of human ASNS and the DON-modified variant were performed at the University of Sheffield Biological Mass Spectrometry Facility. This work was supported by Cardiff University (Y.J. A.R., P.B. and N.G.J.R.), the National Institutes of Health [R01 GM111695 to Y.T.], the National Science Foundation [MCB-1157688 to Y.T.], and the UK Biotechnology and Biological Sciences Research Council (BBSRC) (BB/I003703/1 to D.W.R. and BB/P018017/1 to N.G.J.R.). Funding was also provided by the University of Florida Undergraduate Scholar's Program (A.H.B.) and a Short-Term Scientific Mission grant from COST Action CA15135 (A.C.).

\section{Author contributions}

W.Z., C.B., and S.E.S.: performed purification and crystallization of human ASNS. W.Z and C.B.: performed crystallographic studies and obtained the refined X-ray crystal structure of human ASNS. W.Z.: performed Dali structural similarity studies, HCT-116 transcriptome analysis and kinetic characterization of the ASD-linked ASNS variants. T.I., S.W., F.M.M. and Y.T.: designed the baculovirus constructs and expressed the recombinant forms of human ASNS and human ASS1. A.R.: performed the inhibitor stability measurements, computational modeling studies and free energy calculations. B.E.N. and T.K.N.: devised and performed the chemoproteomic profiling experiments. Y.J., P.B., A.C. and A.H.B.: performed kinetic/inhibition assays on WT human ASNS and site-specific variants. W.Z., J.W.K., D.W.R., Y.T. and N.G.J.R.: designed the study. W.Z., Y.T. and N.G.J.R.: wrote the manuscript with contributions from all other authors.

\section{Additional information}

Supplementary information accompanies this paper at https://doi.org/10.1038/s42003 019-0587-z.

Competing interests: The authors declare no competing interests.

Reprints and permission information is available online at http://npg.nature.com/ reprintsandpermissions/

Publisher's note Springer Nature remains neutral with regard to jurisdictional claims in published maps and institutional affiliations.

Open Access This article is licensed under a Creative Common Attribution 4.0 International License, which permits use, sharing, adaptation, distribution and reproduction in any medium or format, as long as you give appropriate credit to the original author(s) and the source, provide a link to the Creative Commons license, and indicate if changes were made. The images or other third party material in this article are included in the article's Creative Commons license, unless indicated otherwise in a credit line to the material. If material is not included in the article's Creative Commons license and your intended use is not permitted by statutory regulation or exceeds the permitted use, you will need to obtain permission directly from the copyright holder. To view a copy of this license, visit http://creativecommons.org/ licenses/by/4.0/

(C) The Author(s) 2019 